\title{
Unbalanced Peptidergic Inhibition in Superficial Neocortex Underlies Spike and Wave Seizure Activity
}

\author{
도. Hall, ${ }^{1}$ M. Hunt, ${ }^{1}{ }^{\circledR}$ A. Simon, ${ }^{1}$ L.G. Cunnington, ${ }^{2}$ L.M. Carracedo, ${ }^{2}$ I.S. Schofield, ${ }^{3}{ }^{\circledR R}$ R. Forsyth, ${ }^{3}$ R.D. Traub, ${ }^{4}$ \\ and M.A. Whittington ${ }^{1}$ \\ ${ }^{1}$ HYMS, University of York, Heslington, YO10 5DD, United Kingdom, ${ }^{2}$ ION, Newcastle University, Newcastle upon Tyne, NE2 4HH, United Kingdom, \\ ${ }^{3}$ Regional Neurosciences Centre, Newcastle General Hospital, Newcastle, NE4 6BE, United Kingdom, and ${ }^{4}$ Department of Physical Sciences, IBM T.J. \\ Watson Research Center, Yorktown Heights, New York 10598
}

\begin{abstract}
Slow spike and wave discharges $(0.5-4 \mathrm{~Hz})$ are a feature of many epilepsies. They are linked to pathology of the thalamocortical axis and a thalamic mechanism has been elegantly described. Here we present evidence for a separate generator in local circuits of associational areas of neocortex manifest from a background, sleep-associated delta rhythm in rat. Loss of tonic neuromodulatory excitation, mediated by nicotinic acetylcholine or serotonin (5HT3A) receptors, of 5HT3-immunopositive interneurons caused an increase in amplitude and slowing of the delta rhythm until each period became the "wave" component of the spike and wave discharge. As with the normal delta rhythm, the wave of a spike and wave discharge originated in cortical layer 5. In contrast, the "spike" component of the spike and wave discharge originated from a relative failure of fast inhibition in layers $2 / 3$ - switching pyramidal cell action potential outputs from single, sparse spiking during delta rhythms to brief, intense burst spiking, phase-locked to the field spike. The mechanisms underlying this loss of superficial layer fast inhibition, and a concomitant increase in slow inhibition, appeared to be precipitated by a loss of neuropeptide $Y$ (NPY)-mediated local circuit inhibition and a subsequent increase in vasoactive intestinal peptide (VIP)-mediated disinhibition. Blockade of NPY Y1 receptors was sufficient to generate spike and wave discharges, whereas blockade of VIP receptors almost completely abolished this form of epileptiform activity. These data suggest that aberrant, activity-dependent neuropeptide corelease can have catastrophic effects on neocortical dynamics.
\end{abstract}

Key words: epilepsy; inhibition; neuropeptides; sleep; spike and wave discharges

\section{Introduction}

Spike and wave (SpW) discharges manifest on a continuum of pathologies, increasing in severity from BECTS (benign childhood epilepsy with centrotemporal spikes), through to continuous spike and wave discharges during sleep (CSWS). They are also associated with a range of diagnoses, such as absence epilepsies, Lennox-Gastaut syndrome, Landau-Kleffner syndrome, Rett syndrome, autistic regression and fragile-X mutations (Kluger et al., 1996; Medeiros et al., 2010; Chhun et al., 2011; Hughes, 2011). A robust feature of SpW is the concurrent involvement of thalamic and neocortical systems (Steriade et al., 1985, 1993; Huntsman et al., 1999; Crunelli and Leresche, 2002),

\footnotetext{
Received 0ct. 14, 2014; revised May 11, 2015; accepted May 12, 2015

Author contributions: M.A.W. designed research; S.H., M.H., A.S., L.G.C., L.M.C., I.SS., R.F., R.D.T., and M.A.W. performed research;S.H., M.H., R.D.T., and M.A.W. analyzed data; R.D.T. and M.A.W. wrote the paper.

This work was supported by the Wellcome Trust, and R.D.T. was supported by IBM and NIH/NINDS (R01 NS44133).

The authors declare no competing financial interests.

This article is freely available online through the J Neurosci Author Open Choice option.

Correspondence should be addressed to M. A. Whittington, Hull York Medical School, University of York, Heslington, Y010 5DD, UK. E-mail: Miles.whittington@hyms.ac.uk.

L. M. Carracedo's present address: Lilly UK, Erl Wood Manor, Windlesham, Surrey, GU20 6PH, UK.

DOI:10.1523/JNEUROSCI.4245-14.2015

Copyright (C) 2015 Hall et al.

This is an Open Access article distributed under the terms of the Creative Commons Attribution License Creative Commons Attribution 4.0 International, which permits unrestricted use, distribution and reproduction in any medium provided that the original work is properly attributed.
}

prompting detailed models of dysfunction along this axis, with an emphasis on aberrant outputs from thalamic nuclei (Destexhe, 1998; Destexhe et al., 1999).

Some studies provide evidence that a neocortical focus may also underlie SpW discharges. Mouse models with genetically altered calcium channels suggest that rebound burst firing in thalamic reticular nucleus is not required for $\mathrm{SpW}$ generation (Lee et al., 2014) and neuroimaging studies show that abnormal activity in neocortex precedes thalamus (Seneviratne et al., 2014). The suggestion that neocortex is key to SpW generation is supported by earlier animal model work demonstrating that $\mathrm{SpW}$ discharges could be generated by disinhibition of the superficial layers of neocortex alone (Van Duijn et al., 1973): disinhibition at the cortical surface generates SpW whereas ventriculocisternal disinhibition does not (Fisher and Prince, 1977). Furthermore, evidence supports a focal origin of SpW within neocortex despite SpW discharges being associated with "primary generalized" seizures (van Luijtelaar et al., 2014) and the location of the focus correlates with the nature of cognitive deficits seen in children (Bölsterli Heinzle et al., 2014). In general, SpW discharges are seen within hub-regions forming part of the default mode network (Archer et al., 2014), and metabolic studies show that changes in neocortical regions involved in the default mode network are not accompanied by metabolic alterations in thalamus (Ligot et al., 2014). 
In terms of mechanism, selectively boosting $\mathrm{GABA}_{\mathrm{B}}$ receptormediated inhibition generates SpW (Snead, 1991; Destexhe, 1998). Genetic models, such as GAERS and Stargazer rodents, suggest a role for enhanced NMDA receptor function (Lacey et al., 2012) which correlates with genetic abnormalities in human BECTS patients (Carvill et al., 2013). In addition, nicotinic receptor agonists reduce or abolish ongoing SpW generation in a rat genetic models (Danober et al., 1993) and D-tubocurarine generates SpW de novo when injected intracerebroventricularly (Dajas et al., 1983).

This diversity of systems implicated in SpW generation, both in terms of anatomy and neuromodulation/transmission, makes the interpretation of an underlying mechanism for SpW generation difficult. This is particularly the case when considering genetic animal models in which SpW can dominate but occur at higher frequencies than typically seen in humans $(6-9 \mathrm{~Hz}$ vs 0.5-3 Hz; Sasa et al., 1988; Niedermeyer, 2005; Pearce et al., 2014), suggesting a potentially different mechanism. Here we use an isolated neocortex slice preparation, allowing ablation of thalamocortical dialogue (Crunelli and Hughes, 2010), to show that rat local neocortical networks are capable of generating slow $(\sim 1 \mathrm{~Hz})$ SpW under selective perturbation of predominantly superficial-layer interneurons coreleasing VIP and NPY. Furthermore, the spike and wave components of SpW are shown to be interrelated but generated by different laminar subcircuits.

\section{Materials and Methods}

For all data SpW were defined according to the originally described "dart and dome" waveform structure (Lennox and Davis, 1950; Fig. 1D).

\section{In vitro methods}

Electrophysiology. All surgical procedures were performed in accordance with the regulations of the United Kingdom Animals (Scientific Procedures) Act, 1986. Secondary somatosensory/parietal area coronal slices (450 $\mu \mathrm{m}$ thick) were prepared from adult male Wistar rats $(\sim 200 \mathrm{~g})$. Slices were maintained at $34^{\circ} \mathrm{C}$ in a standard interface recording chamber containing oxygenated ACSF consisting of the following (in $\mathrm{mM}$ ): 126 $\mathrm{NaCl}, 3 \mathrm{KCl}, 1.25 \mathrm{NaH}_{2} \mathrm{PO}_{4}, 1 \mathrm{MgSO}_{4}, 1.2 \mathrm{CaCl}_{2}, 24 \mathrm{NaHCO}_{3}$, and 10 glucose. Persistent, spontaneous delta oscillations were generated as described previously (Carracedo et al., 2013). Further perfusion of the following antagonists was performed in certain experiments; \pm Tubocurarine chloride (10 $\mu \mathrm{M}$, nicotinic acetylcholine and $5-\mathrm{HT}_{3}$ receptors), MDL72222 (10 $\mu \mathrm{M}, 5-\mathrm{HT}_{3}$ receptors), BMS193885 (10 $\mu \mathrm{M}$, NPY receptors), [D-p-Cl-Phe6, Leu17]-VIP ( $1 \mu \mathrm{M}$, VIP receptors). In addition a range of nicotinic receptor subunit-specific agents was used: MG624 ( $N, N, N$-triethyl-2-[4-(2-phenylethenyl)phenoxy]ethanaminium), $\alpha 7$ containing nicotinic acetylcholine receptors (nAchR; Gotti et al., 1998); pancuronium $\left(\alpha 7^{\star}\right.$-containing nAchR; neuromuscular junction-subtype; Tsuneki et al., 2003$)$; dihydro- $\beta$-erythroidine ( $\alpha 4$-containing nAchR; Williams and Robinson, 1984); ACV1 (conotoxin Vc1.1, $\alpha 9 / 10-$ containing nAchR; Halai et al., 2009); $\alpha$-conotoxin Pn1A ( $\alpha 3 \beta 2$ nAchR; Luo et al., 1999); $\alpha$-conotoxin Au1B ( $\alpha 3 \beta 4$ nAchR; Luo et al., 1998; see Fig. 4). Drugs were obtained from Santa Cruz Biotechnology, Tocris Bioscience, or Sigma-Aldrich.

Extracellular field recordings were obtained using micropipettes (2-5 $\mathrm{M} \Omega$ ) filled with ACSF and were bandpass filtered at 0.1-300 Hz. Intracellular recordings were obtained using micropipettes (50-150 M $\Omega$ ) filled with $2 \mathrm{M}$ potassium acetate and $2-4 \mathrm{~m}$ biocytin (Santa Cruz Biotechnology) and were recorded DC $-2.5 \mathrm{kHz}$. Power spectra were derived from Fourier transform analysis of $120 \mathrm{~s}$ epochs of data and results were presented as mean \pm SEM. Spike detection was performed using Axograph and based on transient deflections from the mean membrane voltage. Fast and slow inhibition estimates were calculated by using a Savitzky-Golay differential filter of membrane potential changes at -30 $\mathrm{mV}$ for each SpW event. Filter settings were tuned to separate highfrequency events (rise time/decay time $=2-30 \mathrm{~ms}$ ) from lower frequency events (rise time/decay time 30-1000 ms). Resulting waveforms were then integrated below an envelope of local peak positivities for the duration of each delta/SpW event. Example outputs are shown in Figure 7Aii.

Immunohistochemistry. Upon termination of electrophysiological experiments, slices were immediately fixed in $4 \%$ buffered paraformaldehyde $/ 15 \%$ picric acid solution and stored for at least $48 \mathrm{~h}$ at $4^{\circ} \mathrm{C}$. Slices were washed, then resectioned at $40-60 \mu \mathrm{M}$ with a vibratome (VT1000S; Leica Microsystems). Sections were permeabilized then incubated with primary antibodies for 5- $\mathrm{HT}_{3 \mathrm{~A}}$ (AbCam), NPY (AbCam), and VIP (Millipore) in a blocking solution overnight. The following day sections were washed and incubated with secondary antibodies; AlexaFLuor 488 Goatanti-Rabbit, AlexaFluor 568 sheep-anti-donkey and AlexaFluor 647 goat-anti-guinea-pig respectively for $2 \mathrm{~h}$. Biocytin filled cells were visualized by using AlexaFluor 405 Streptavidin conjugate (AbCam). Slices were mounted using VectaShield (Vector Laboratories) and fluorescence pictures were taken using a Zeiss 780 upright confocal microscope. Once fluorescence was measured, biocytin-filled cells were revisualized for light microscopy using the standard DAB peroxidase method (Vector Laboratories).

\section{In vivo methods}

Surgery. Four male Wistar rats (250-350 g) were implanted with a 22 gauge stainless steel infusion guide (Bilaney) and pairs of stainless steel electrodes insulated, except at the tip (125 $\mu \mathrm{m}$, Science Products), glued alongside the medial and lateral side of the guide in the secondary somatosensory (parietal) cortex (AP -2.0, ML 4.0, DV $5.0 \mathrm{~mm}$, lateral angle of $25^{\circ}$ ); an association area known to generate strong delta rhythms in rodent and human (Ioannides et al., 2009; Carracedo et al., 2013). Skull screws, for ECoG recordings, were placed above the frontal and parietal cortex. One rat was implanted with an electrode/guide complex consisting of an array of six stainless steel electrodes each tip separated by $\sim 400 \mu \mathrm{m}$ in the horizontal plane. In all cases, a skull screw posterior to the bregma was used as ground/reference electrode.

Recording. Recordings of freely moving rats were taken from 9:00 A.M.-4:00 P.M. Local field potentials (LFPs) and ECoGs were recorded through a JFET preamplifier. The signal was relayed through a commutator (Crist Instruments), filtered at DC $-1.2 \mathrm{kHz}$ and digitized at 2.8 $\mathrm{kHz}$ (AlphaLab, Alpha-Omega). For infusion, cannulae (28 gauge, Bilaney) that extended $2 \mathrm{~mm}$ below the tip of the guide were inserted and left in place for $60 \mathrm{~s}$, followed by infusion of tubocurarine $(0.2$ or $0.5 \mu \mathrm{g}$; $1 \mu \mathrm{l} ; 0.5 \mu \mathrm{l} / \mathrm{min}$ ) and left in place for a further $60 \mathrm{~s}$. Rats were then reconnected and LFP/ECoG's were recorded until cessation of SpW activity.

Analysis. SpW events were extracted from LFPs by wavemark template matching with threshold $>4$ SD from baseline (Spike 2, Cambridge Electronic Design and MATLAB). Correct identification of SpW was confirmed by an experimenter. The summed degree of template-matching over a $10 \mathrm{~s}$ epoch during continuous $\mathrm{SpW}$ events was used as an estimate of SpW intensity in human EEG data and color mapped to generate the spatial localization figure shown in Figure 1Aii. In rats tubocurarineinduced SpW could be separated into two stages: an initial stage where SpW occur almost continuously (frequency close to $2 \mathrm{~Hz}$, CSWS-like activity; Fig. 1$)$ and a later stage ( $\sim 30$ min postinfusion) where their occurrence was more sporadic. Rate of SPW events was related to four behavioral states: (1) active waking (AW) was characterized by exploratory behavior, such as rearing and locomotion and was accompanied by desynchronized frontal ECoG and theta oscillations in the parietal ECoG. (2) Quiet waking (QW) was characterized by stereotypic behavior, such as grooming, or inactivity with eyes open, which was accompanied by slow oscillatory activity in frontal and parietal ECoGs. (3) Slow-wave sleep (SWS) was characterized by high voltage slow oscillatory activity in frontal and parietal ECoGs. (4) Rapid eye movement (REM) sleep was characterized by desynchronized frontal ECoGs and theta in the parietal ECoG.

\section{Computational model}

We simulated a cortical column (without the thalamic portion), based on a program described by Traub et al. (2005). The present model included 1000 superficial regular spiking (RS) pyramids, 50 superficial fast rhythmic bursting (or chattering) pyramids, 90 superficial basket cells, 90 
$\mathbf{A}_{\mathbf{i}}$

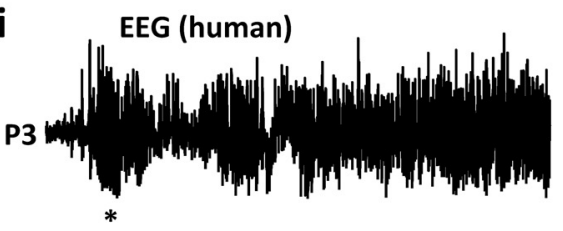

ii

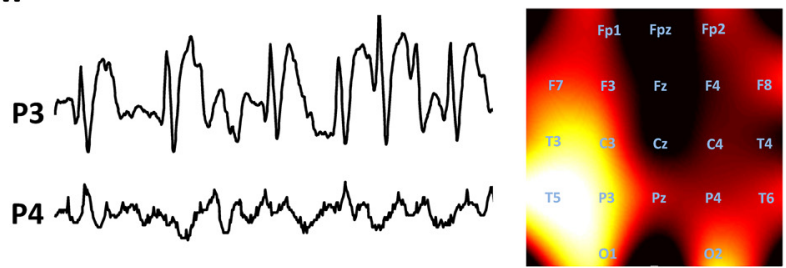

ii

$\mathbf{B}_{\mathbf{i}}$

ipsi
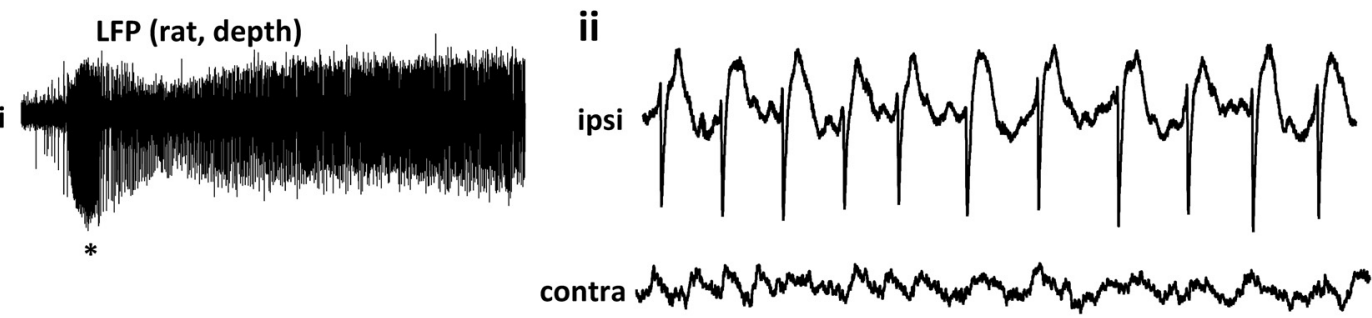

ii

$\mathbf{c}_{\mathbf{i}}$ LFP (rat, in vitro)

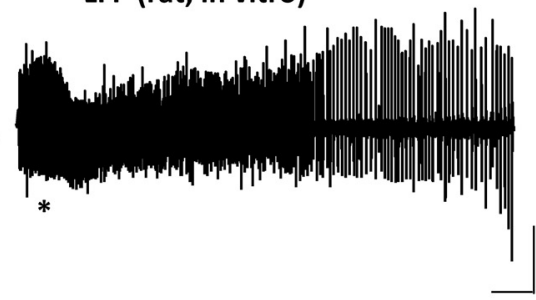

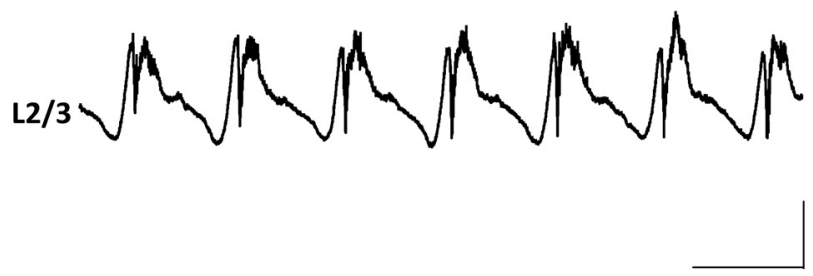

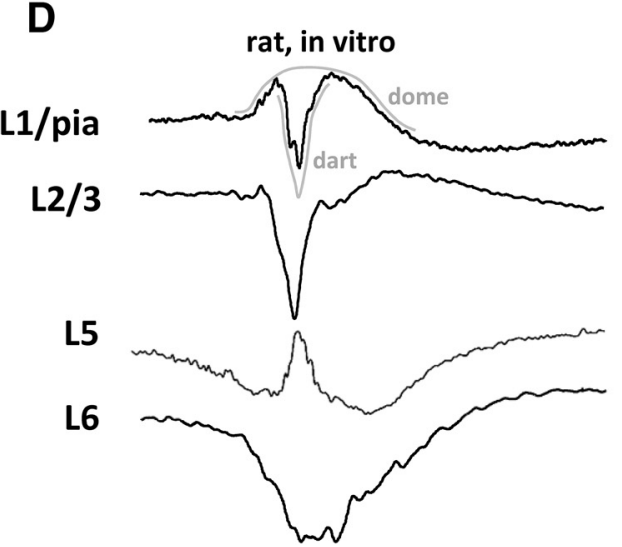

rat, in vivo
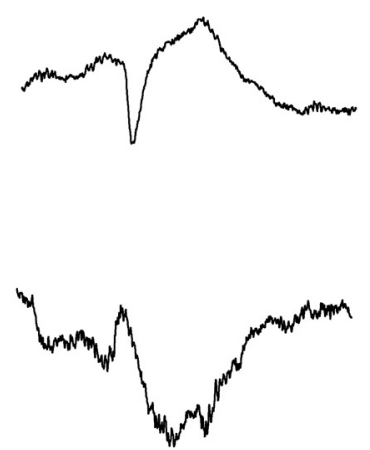

model
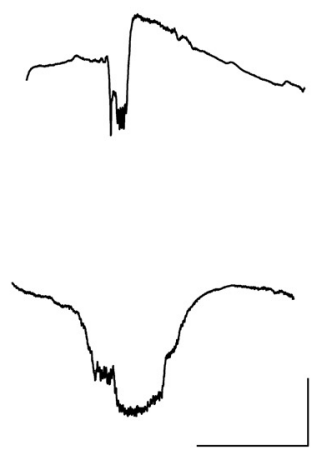

Figure 1. SpW discharges can be a local neocortical phenomena. $\boldsymbol{A}-\boldsymbol{C}$, Intense, continuous SpW generation in humans can have features that can be captured by direct cortical application of tubocurarine in rat. Ai, EEG recording from P3 in a child with BECTS-like seizures (benign epilepsy with centrotemporal spikes) manifesting on sleep-wake transitions. Aii, Expanded portion of the left trace (asterisk) showing typical continuous spike and wave discharges. Concurrent EEG activity from the contralateral parietal cortex (P3) demonstrates a strong lateralization of the epileptiform event. Inset shows localization of these events to the right temporoparietal region. Hotter colors represent more intense SpW. Bi, Local infusion of tubocurarine, via cannula into rat superficial parietal cortex $(0.2 \mu \mathrm{g}$ in $1 \mu \mathrm{l})$, generated intense, long-lasting continuous SpW activity. Bii, As with the human EEG recordings, tubocurarine elicited continuous spike and wave discharges with no contralateral generalization. Ci. Bath application of tubocurarine $(10 \mu \mathrm{m})$ to isolated parietal cortex slices maintained in vitro also generated intense epileptiform discharges. Cii, Expanded trace showing superficial layer (L2/3) local field potential recording of continuous SpW discharges. D, The waveform shape of the SpW was highly layer-specific. Left panel shows reversal of both the spike ('dart') and wave ('dome') component of the SpW, according to the original nomenclature (Lennox and Davis, 1950), when recording from both superficial (pia-L3) and deep (L5-L6) laminae in isolated parietal cortex slices. Middle panel shows comparable data from electrode pairs in superficial and deep parietal cortex during slow-wave sleep in vivo. Right panel shows the output from the computational model in which membrane potential changes in superficial and deep layer pyramidal cells were inverted and averaged to give a field potential estimate. Scale bars Ai-Ci: 10,30,200 $\mu \mathrm{V}, 20$ s. Aii-Cii: $10,30,200 \mu \mathrm{V}, 1$ s. D, left $150 \mu \mathrm{V}$, middle $20 \mu \mathrm{V}$, right arbitrary, $200 \mathrm{~ms}$.

superficial axoaxonic interneurons, 90 superficial LTS (low-threshold spiking) interneurons, 240 spiny stellate cells, 2000 deep tufted IB (intrinsic bursting) pyramids, 500 deep nontufted RS pyramids, 100 deep basket cells, 100 deep axoaxonic cells, 100 deep LTS interneurons; all with intrinsic properties similar to the previous paper. We did not include deep tufted RS cells in the present model. In addition, we now added 90 superficial and 100 deep "neurogliaform" interneurons. Neurogliaform cells were small fast-spiking interneurons with increased soma/dendritic " $\mathrm{A}$ "-type $\mathrm{K}^{+}$conductance, rendering them "delayed-spiking" neurons, in response to an injected current pulse. In our program, neurogliaform 
cells were the only ones to produce postsynaptic $\mathrm{GABA}_{\mathrm{B}}$ conductances (Tamás et al., 2003); they produced $\mathrm{GABA}_{\mathrm{A}}$ conductances as well. Neurogliaform cells were excited by AMPA/kainate receptors and by NMDA receptors.

Neurons were interconnected by chemical synapses and gap junctions. The connectivity of chemical synapses was similar to Traub et al. (2005). In addition, superficial neurogliaform cells contacted all types of pyramidal cells (onto the apical dendrites of deep ones), as well as other superficial neurogliaform and basket cells. Deep neurogliaform cells contacted deep tufted pyramids, spiny stellates, and other deep neurogliaform cells, as well as deep basket cells. AMPA receptor-mediated conductance time courses followed an $\alpha$ function. GABA $\mathrm{A}_{\mathrm{A}}$ conductances rose abruptly and decayed following a single exponential time course. NMDA conductances were described by the formalism of Traub et al. (1994), in which there is a product of a scaling factor, a purely timedependent term, and a voltage- and $\left[\mathrm{Mg}^{2+}\right]$-dependent term (Traub et al. (2005)). GABA $A_{B}$ conductances also followed a formalism from Traub et al. (1994), originally derived from Otis et al. (1993), in which the conductance is zero for $10 \mathrm{~ms}$, and then is a scaling factor multiplied by a time-dependent term ( $t$ in $\mathrm{ms})$ :

$\left[1-\exp (-(t-10) / 38.1]^{4} \times[10.2 \times \exp (-(t-10) / 122)+1.1\right.$

$$
\times \exp (-(t-10) / 587)]
$$

Neurons were also coupled by gap junctions, which were placed only between homologous cell types located on the dendrites of interneurons, and on the axons of principal neurons. Spontaneous activity was driven by ectopic axonal spikes to superficial pyramidal cells (but not deep ones), and by tonic depolarizing currents to the basal dendrites of tufted IB pyramidal cells.

With this basic model, we explored a variety of alterations in synaptic conductances, especially AMPA, $\mathrm{GABA}_{\mathrm{A}}$, and $\mathrm{GABA}_{\mathrm{B}}$; and concentrating on conductances determining recurrent synaptic excitation in superficial layers, as well as synaptic inhibition onto superficial pyramids and the dendrites of deep pyramids.

Differential equations were integrated with a second order Taylor series method, with integration step $2 \mu \mathrm{s}$. Programs were written in Fortran and compiled with the mpxlf command for the mpi parallel environment. Simulations were run on 24 nodes of an IBM 7040-681 AIX parallel machine. Simulation of $3 \mathrm{~s}$ of neural activity took $\sim 31 \mathrm{~h}$. Source code is available from R.D.T. (rtraub@us.ibm.com).

\section{Results}

\section{SpW events are generated in neocortex in a localized, lamina-} specific manner

The long-standing, strong association between SpW and sleep (Angeleri et al., 1968) led us to consider a typical case of CSWS as a reference for validating the in vivo and in vitro models to be used in this study. We present data from a child (age 10) presenting from age 6 with early morning ( 5:00 A.M.) seizures manifesting as gulping, facial weakness, and $\sim 5$ min of slurred speech on waking. Protracted, continuous SpW discharges were observed associated with these mild motor symptoms (frequency $0.7 \pm 0.1$ $\mathrm{Hz}$ ) for $>10$ min with amplitude peaking over left parietal cortex (Fig. 1A, electrode P3). Contralateral parietal electrode recordings, while showing pathological waveforms, did not exhibit overt SpW activity, indicating lateralization of the discharges. We attempted to model this type of epileptiform activity in a nonanesthetized rat in vivo model by local injection of $0.2-0.5 \mu \mathrm{g}$ D-tubocurarine. Acute dTC application generated a rapidly developing continuous $\mathrm{SpW}$ discharge with remarkable similarity to the patient recordings. Depth electrodes in the superficial layers of the injected parietal cortex showed SpW occurrence lasting $>10$ min with a frequency of $0.9 \pm 0.3 \mathrm{~Hz}(n=4)$. Contralateral depth electrodes in the uninjected parietal cortex showed no overt pathology (Fig. 1B).
To investigate the localization of SpW further we bath applied dTC $(20 \mu \mathrm{M})$ while recording from layer 1 of parietal cortex in rat slices on a baseline delta rhythm (see Materials and Methods). As with the patient and in vivo experiments, a rapidly developing period of continuous SpW was seen with a frequency of $0.5 \pm 0.2$ $\mathrm{Hz}$ (Fig. 1C). Unlike the in vivo model, this CSWS-like activity developed over $\sim 1 \mathrm{~min}$ into repetitive polyspike and wave activity (data not shown). Local field potential recordings from different layers in parietal cortex showed a reversal of the spike component of each SpW from negative-going in layers 1-3 to positive-going in layer 5 . In contrast, the wave component of the SpW reversed from positive-going in layer 1 to negative going in layers 5-6. Comparison of depth electrode data in vivo revealed a similar reversal of the spike and the wave components when comparing data from superficial and deep parietal laminae. In addition, model field potentials from the computational model (summed membrane potentials from neuronal subtypes in superficial and deep "layers") also showed a reversal of the wave component and a domination of the spike component in superficial layers (Fig. 1D). These data suggested a differential origin of the spike and the wave component of the SpW, with the wave originating in deep layers and the spike arising from superficial layers, if both are assumed to be mediated by excitatory synaptic events. This was investigated further.

\section{The spike component of SpW was accompanied by burst discharge generation in superficial pyramidal cells}

Intracellular recordings from layer 5 IB neurons and layer $2 / 3$ RS neurons further supported the suggestion from local field potential data that $\mathrm{SpW}$ discharges had distinct components originating from different parietal cortical laminae. The in vitro experimental model was critically dependent on the preexistence of a delta (ca 1-3 Hz) rhythm (Carracedo et al., 2013). In these control conditions, IB neurons generated repetitive burst discharges phase-locked to the field delta rhythm. Bath application of $10 \mu \mathrm{M}$ dTC (NB, half the concentration required to generate the intense CSWS-like discharges shown in Fig. 1) transformed this delta rhythm into spontaneous $\mathrm{SpW}$ with a frequency of $8 \pm 3 \mathrm{~min}^{-1}$ ). During $\mathrm{SpW}$ in these conditions IB neurons continued to generate burst discharges but with significantly longer durations ( $266 \pm 31$ vs $394 \pm 56 \mathrm{~ms}, p<0.05, n=$ 100 events/delta periods from $N=5$ slices; Fig. $2 A$ ). During control delta rhythm, superficial RS neurons generated only zero to two action potentials per delta period. When multiple action potentials were seen they were always separated by $\sim 1$ theta period (Carracedo et al., 2013). In contrast, during SpW, superficial RS neurons generated a single, intense burst of action potentials phase-locked to the onset of the spike component of the SpW. Action potentials numbers per event (one delta period vs one SpW) were $1.2 \pm 0.3$ versus $3.8 \pm 0.2$ and interaction potential intervals were $195 \pm 20$ versus $8 \pm 1 \mathrm{~ms}(p<0.05$ and $p<0.005$, respectively).

This overt transformation from single action potential generation to burst discharges in superficial layer RS neurons was reproduced by the computational model with decreased superficial synaptic inhibition and enhanced fast synaptic excitation (Fig. $2 B)$. These data suggested that the local field potential spike component of each SpW was mediated by the generation of burst discharges in superficial pyramidal cells. This was reinforced by direct correlation of burst action potential generation with field potential spike amplitude (Fig. 2C). Larger spikes in the SpW discharge were accompanied by a greater number of action potentials within the superficial RS neuron burst. The intensity of 


\section{Experiment}

A control

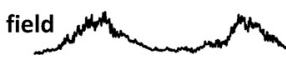<smiles>C#CC#CCCC#CCCCCC#CC#C</smiles>

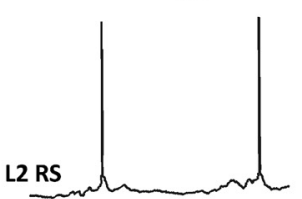

ii Spike and wave
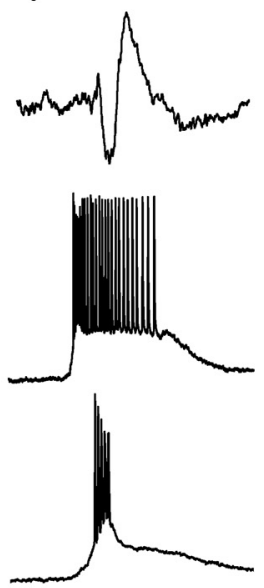

\section{Model}

$\mathbf{B}_{\mathbf{i}}$
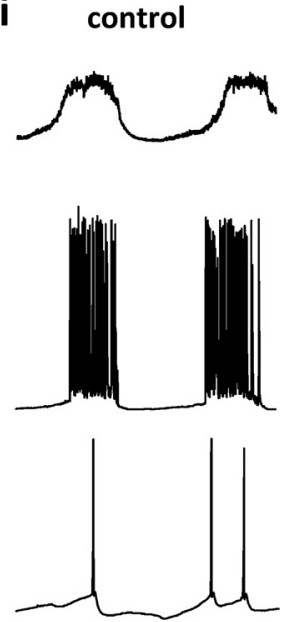

ii Spike and wave
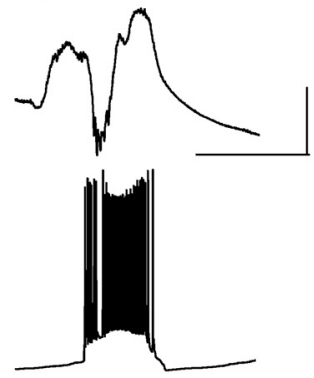

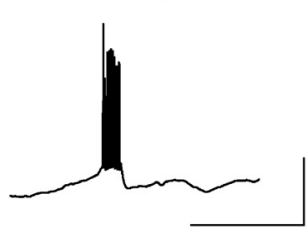

C i

Experiment
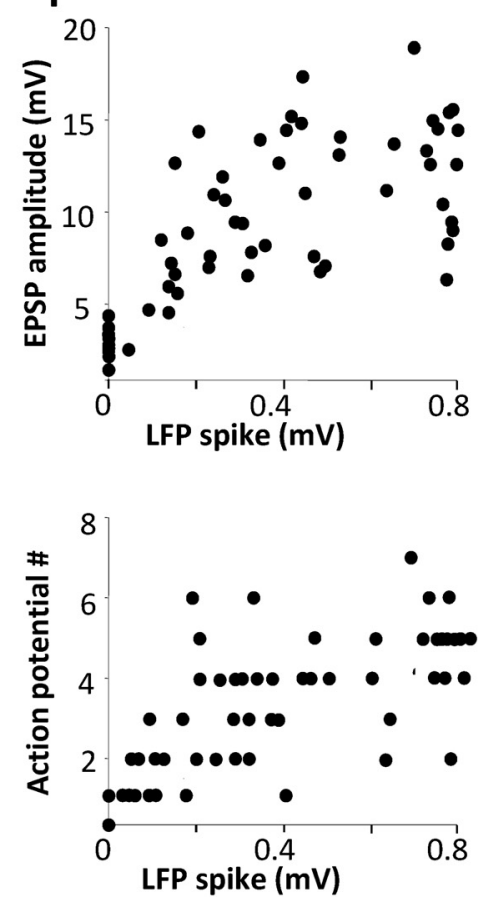

ii

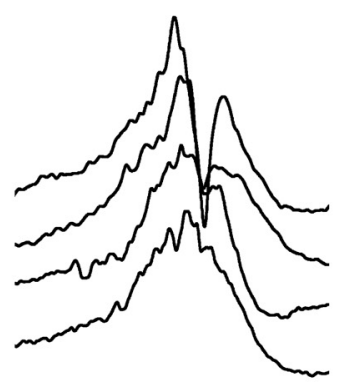

Model

D

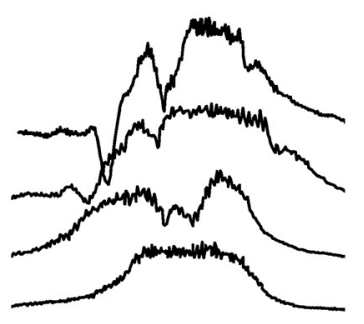

Figure 2. The spike and the wave component of SpW discharges originate in superficial and deep cortical layers respectively. Ai, Control delta rhythms are accompanied by bursting in layer 5 intrinsic bursting neurons (LSIB) but only single or double spikes per period in superficial layer pyramids (L2 RS). Both example intracellular recordings were taken from resting membrane potential (IB $-76 \mathrm{mV}, \mathrm{RS}-65 \mathrm{mV}$ ) and the field was taken from layer 1. Aii, Spontaneous spike and wave discharges induced by bath application of tubocurarine were accompanied by longer duration, more intense L5 IB neuron bursts and a switch from single spike generation to brief, intense bursts in L2 RS neurons. Bi, Bii, Reduced superficial layer fast inhibition and enhanced recurrent AMPA receptor-mediated excitation in a columnar computational model of delta rhythms (Carracedo et al., 2013) transformed delta rhythms to repetitive spike and wave discharges. Model $L 5$ IB neurons generated longer, more intense burst discharges, and superficial layer RS neurons switched to burst generation in agreement with experiment. Ci, Top graph shows layer 2/3 RS neuron peak EPSP amplitudes (taken from membrane potential of $-80 \mathrm{mV}$ ) plotted against layer 1 LFP spike amplitude (peak-trough) for 65 spontaneous SpW events from $n=7$ slices. Bottom graph shows number of action potentials in layer $2 / 3 \mathrm{RS}$ neuron bursts (recorded from resting membrane potential) plotted against LFP spike amplitude as per upper graph for 70 spontaneous SpW events from $n=7$ slices. Cii, Four LFP/EPSP paired recording examples (LFP above, EPSPs below) from the dataset plotted in Ci (top graph). D. Examples of types of SpW obtained from the computational model. Top traces show model field potentials. Bottom traces show superficial layer RS neuron AMPA receptor-mediated excitatory input. Four situations were modeled. Working down from upper trace pairs: superficial RS neurons receive excitatory input from both L5 IB neurons and other superficial RS cells (all); superficial RS neurons receive excitatory input from other superficial RS neurons only (L2/3-L2/3); superficial layer excitatory input form L5 only (L5-L2/3); no AMPA-mediated excitation to superficial RS neurons. Note the large, sharp EPSPs originated from superficial layer recurrent connections and the long, slow compound EPSP derived from ascending excitation form L5. Scale bars: $A, B, 0.3 \mathrm{mV}$ (field), $20 \mathrm{mV}$ (intracellular recordings and model examples), $0.3 \mathrm{~s}$; (ii, $\boldsymbol{D}, 0.1 \mathrm{mV}$ (field), $10 \mathrm{mV}$ (EPSPs). 

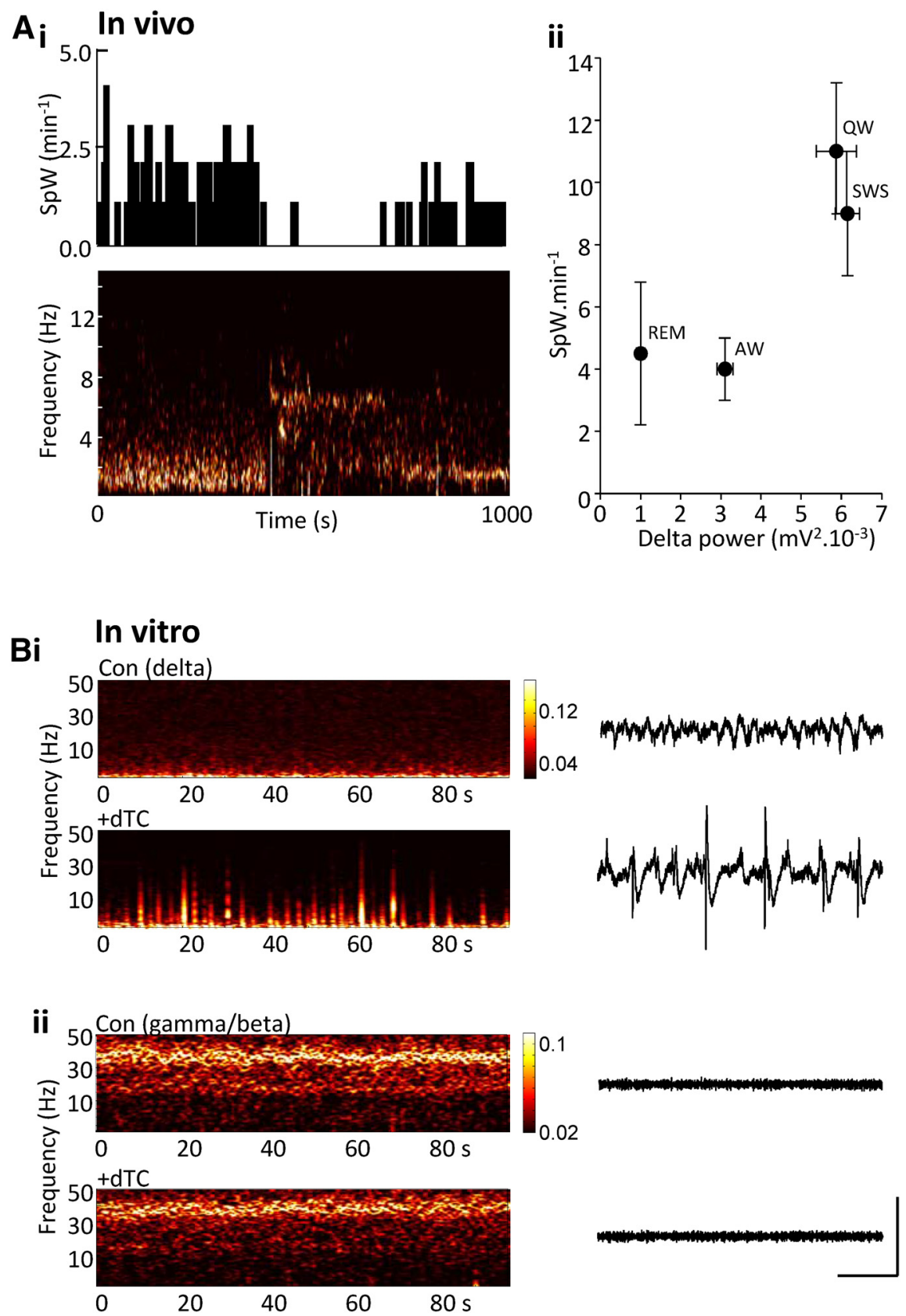

Figure 3. SpW occur only in the presence of strong delta rhythms. $A$, Correlation between SpW incidence and behavioral state in rat in vivo recordings $30 \mathrm{~min}$ following tubocuraine injection. $\boldsymbol{A i}$, Top graph shows single example of SpW counts from a superficial Par2 in a rat showing incidence change from SWS to AW and back to SWS over ca $17 \mathrm{~min}$. Bottom spectrogram shows corresponding contralateral EEG frequency content over contralateral parietal cortex. Note the transition from delta to theta and higher frequencies was accompanied by a marked reduction in SpW incidence. Aii, Pooled data from five rats plotting mean SpW incidence against mean delta power for four behavioral states. $\boldsymbol{B}, \mathrm{SpW}$ incidence also correlated with delta power in vitro. $\boldsymbol{B i}$, Spectrograms from $1.5 \mathrm{~min}$ of data from a single experiment showing frequency content from 0 to $50 \mathrm{~Hz}$ for recording from layer 5 of parietal cortex slices without [con (delta)] and with bath application of tubocurarine (+dTC). Note the occurrence of SpW discharges is accompanied by transient elevations in power above the delta band. Example traces show 10 s of LFP activity in both conditions. Bii, Spectrograms from $1.5 \mathrm{~min}$ of data from a single experiment showing frequency content from 0 to $50 \mathrm{~Hz}$ for recording from layer 5 of parietal cortex slices in the presence of kainate ( $400 \mathrm{~nm}$ ) to induce persistent gamma/ $\beta$ rhythms, without delta activity. Data are shown without [con (gamma/ $\beta$ )] and with bath application of tubocurarine ( $+\mathrm{dTC})$. Note the complete absence of SpW discharges in either condition. Example traces show $10 \mathrm{~s}$ of LFP activity in both conditions. Scale bars: $1 \mathrm{mV}, 2 \mathrm{~s}$.

the action potential burst was, in turn, strongly linearly correlated with the peak amplitude of the compound EPSP these neurons received during SpW $\left(r^{2}=0.85, p<0.05 ;\right.$ Fig. $\left.2 C i\right)$. We used the computational model to predict the origin of the EPSPs underlying superficial RS neuron bursts by selectively removing superfi- cial layer recurrent connectivity between RS neurons, ascending excitation from layer 5 IB neurons, or both (Fig. 2D). These simulations showed that the temporally discrete, large EPSP associated with the spike in SpW came almost exclusively from excitatory connections between RS neurons within the superficial cortical layers.

The occurrence of $\mathrm{SpW}$ was associated with a pre-existing delta rhythm The data from layer-specific field potential and intracellular recordings both suggested that $\mathrm{SpW}$ were essentially deranged delta periods. The wave component corresponded to the same (albeit more intense) rhythmic burst discharges in layer 5 IB neurons and the computational model predicted that selective enhancement of fast excitation and reduction in fast inhibition in superficial layers gave rise to the spike (see above). If this was the case then the incidence of SpW should be correlated with the amount of background delta activity in parietal cortex. We first tested this in behaving rats in vivo. Using skull screw EEG recordings over parietal cortex we quantified the amount of delta activity, and other spectral content, and related this to the incidence of SpW recorded using depth electrodes (Fig. 3Ai). Further correlation with observed behavioral state allowed an estimate of arousal in each animal. These data showed a significant, near-doubling of the incidence of SpW when comparing high-delta power states (QW, SWS; Fig. 3Aii) with low delta power states (REM and AW, $p<0.05$, $n=5)$.

These data showed at least a partial dependence on delta rhythms for generation of SpW. However, delta power is never completely absent in vivo in cortex and indeed plays an important role in sensory processing in the awake state (Schroeder and Lakatos, 2009). We therefore turned to the in vitro model, where spectral content can be controlled experimentally with more precision than reliance on behavioral state. In this series of experiments bath application of $10 \mu \mathrm{M}$ dTC to parietal cortical slices generating the type of neocortical delta rhythms used in the present model (generated through low cholinergic/zero dopaminergic neuromodulation levels as in Carracedo et al., 2013) reliably induced spontaneous $\mathrm{SpW}$ with mean incidence of $5.5 \pm 1.2 \mathrm{~min}^{-1}(n=7$; Fig. $3 B)$. In complete contrast, when dTC, at this concentration, was applied to control (inactive) slices no SpW were see (data not shown). In addition, even when activity was present, but not at delta frequencies, no $\mathrm{SpW}$ were seen: following induction of gamma/ $\beta$ rhythms with 


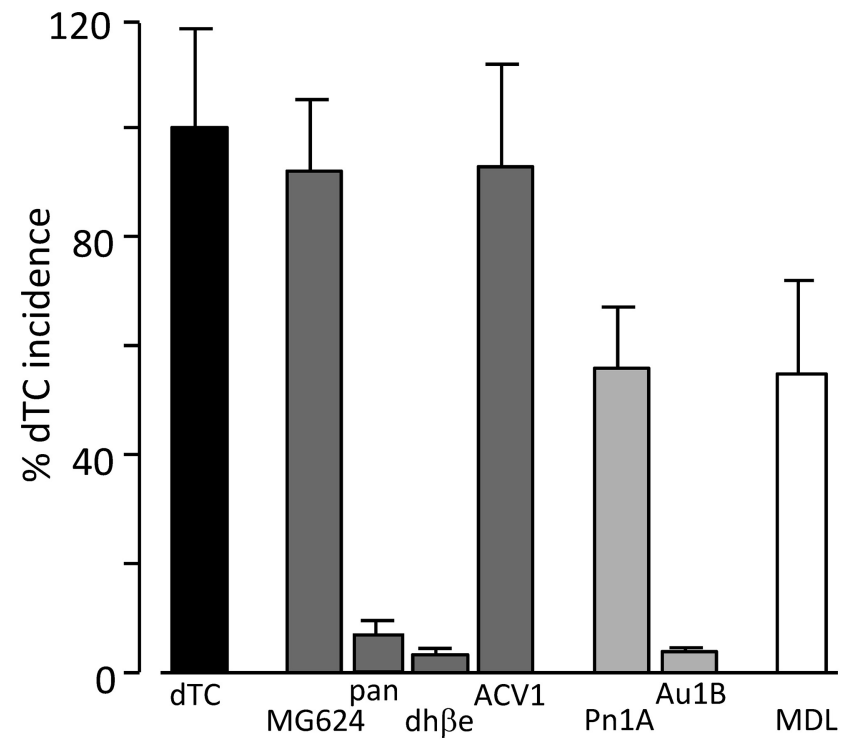

Figure 4. Pharmacological generation of SpW suggests specific nicotinic and serotoninergic receptor subtypes. Graph shows mean $(n=5-7)$ incidence of SpW from a delta rhythm baseline in various pharmacological conditions normalized to the mean incidence generated by tubocurarine (dTC). Selective antagonism of subtypes of nicotinic and serotoninergic receptors was attempted by bath application of the following drugs: MG624, pancuronium, dihydro- $\beta$ erythroidine, ACV1 (dark gray bars) to select for different $\alpha$-subunits; $\alpha$-conotoxin Pn1A, $\alpha$-conotoxin Au1B (light gray bars) to examine the effects of different $\beta$ subunits); MDL72222 (white bar) to compare with 5- $\mathrm{HT}_{3}$ serotoninergic receptor blockade alone. All drugs were added at a concentration of $10 \mu \mathrm{m}$. Note the profile of nicotinic receptor subunit effects corresponds to those reported to be present on $5-\mathrm{HT}_{3}$-immunopositive interneurons in neocortex (Lee et al., 2010).

bath application of kainate $(400 \mathrm{nM}) \mathrm{SpW}$ rates were zero in all of the slices tested $(n=5$; Fig. $3 C$ ). In this condition even electrical stimulation $(40 \mathrm{~V}, 50 \mu$ s delivered through bipolar electrodes to superficial neocortex) failed to generate SpW (data not shown).

\section{Generation of SpW depended on selective antagonism of nAchRs and/or $5-\mathrm{HT}_{3}$ receptors}

The most overt change in local neocortical neuronal behavior observed on generation of SpW was the intense hyperexcitability of superficial layer RS neurons (see above). The computational model predicted that this could be a consequence of reduced $\mathrm{GABA}_{\mathrm{A}}$ receptor-mediated inhibition in superficial layers and enhanced superficial layer recurrent excitation. As superficial neocortical layers obtain most of their inhibition through a subset of interneurons derived from the caudal ganglionic eminence (Lee et al., 2010; Vucurovic et al., 2010) we used at least partially selective pharmacological tools to manipulate their sensitivity to excitation through $5-\mathrm{HT}_{3}$ and nAch receptors (Fig. 4). D-tubocurarine itself has antagonist actions at both of these receptor subtypes (Yan et al., 2006) so its ability to generate SpW was used as a reference for other, more selective agents. Bath application of MG624 or ACV1 (blockade of $\alpha 7$ - or $\alpha 9 / 10$ containing nicotinic receptors generated SpWs with incidence not significantly different from dTC $(p>0.1, n=5)$. In contrast, bath application of pancuronium or dihydro-b-erythroidine (blockade of neuromuscular junction-type or $\alpha 4$-containing nicotinic receptors) had almost no SpW-inducing effect when administered alone. Addition of the conotoxin Pn1A did generate $\mathrm{SpW}$, but with a lower incidence than dTC, whereas the conotoxin Au1B had significantly less effect $(p<0.05, n=5$; see Discussion). As nAchRs are expressed in some principal cells, in deep as well as superficial layers, and are found presynaptically, we next tried blocking only $5-\mathrm{HT}_{3}$ receptors as these are found only on interneurons predominantly in layers $1-3$ in neocortex. Addition of the $5-\mathrm{HT}_{3}$ receptor antagonist MDL72222 alone generated SpW with an incidence of $\sim 50 \%$ of that seen with dTC. From this, the main candidates for reduced superficial cortical layer inhibition predicted to underlie SpW appeared to be those excited by both $5-\mathrm{HT}_{3} \mathrm{Rs}$ and nAchRs.

VIP- and NPY-containing superficial layer interneurons were differentially affected by SpW generation

To investigate further the role of superficial parietal cortical interneurons we recorded from two electrophysiologically distinct interneuron subtypes during control delta rhythms and SpW. Fast adapting interneurons (FA) had a mean membrane potential during delta rhythms of $-79 \pm 3 \mathrm{mV}(n=15)$, and fired intense bursts of action potentials on current injection that were rapidly truncated. These cells also possessed a large, very slow, late afterhyperpolarization (AHP; Fig. 5A). In contrast, slow adapting interneurons (SA) had a more depolarized mean membrane potential during control delta rhythms $(-69 \pm 2 \mathrm{mV}, n=12)$, fired action potentials with slower postspike AHP than the FA cell subtype but with a much reduced late AHP (Fig. 5B). In addition, SA neurons, but not FA neurons, had overt afterdepolarizations, which often resulted in paired action potential generation. Biocytin reconstructions showed a mainly stellate-like dendritic arbour for FA neurons whereas SA neurons were more bipolar, with main dendritic branches arranged radially across the entire layer $2 / 3$.

Immunocytochemical characterization of FA neurons revealed them to be weakly immunopositive for $5-\mathrm{HT}_{3}$ receptors but strongly immunopositive for VIP. No signal was seen when using NPY-specific antibodies (Fig. 5C). In contrast, SA neurons were strongly immunopositive for $5-\mathrm{HT}_{3}$ receptors and had the opposite peptidergic profile: being immunopositive for NPY but not VIP (Fig. 5D)

This contrasting peptidergic profile was mirrored by a contrasting level of recruitment in control delta rhythms (Fig. 6). VIP-immunopositive FA neurons were completely silent during delta. No action potentials were observed at all during $\sim 1 \mathrm{~h}$ of recordings from $n=15$ neurons (Fig. $6 B$ ). This was seen despite these cells receiving clear, compound EPSPs on each delta period (peak EPSP amplitude at $-70 \mathrm{mV}$ was $1.8 \pm 0.1 \mathrm{mV}$ ). NPYimmunopositive SA neurons were strongly recruited into the control delta rhythm, generating bursts of action potentials on each delta period with a mean interspike interval of $32 \pm 2 \mathrm{~ms}$; Fig. $6 C$ ). The contrasting levels of recruitment of FA and SA neurons appeared to be related to both their different mean membrane potentials during delta rhythms (see above), and the relatively small size of their EPSP inputs: SA mean peak EPSP amplitude was $5.7 \pm 0.1 \mathrm{mV}(p<0.05$, compared with those observed in FA neurons).

Further differences between these two interneuron subtypes were observed on transition to SpW. FA neurons, previously completely quiescent during control delta, generated 1-2 action potentials aligned to the spike in SpW. This output was associated with receipt of near tenfold larger EPSPs during SpW (17.2 \pm 0.8 $\mathrm{mV}, p<0.05$ compared with delta-related EPSPs) and also a strong, tonic depolarization (see below). In contrast, SA neuron outputs decreased significantly on transition from delta to SpW. Action potential generation on each delta period was reduced to only a brief period of action potential generation seen aligned to the spike in SpW (mean action potential number $2.2 \pm 0.3 \mathrm{mV}$, $p<0.05)$. This decrease in output from this interneuron subtype 
A

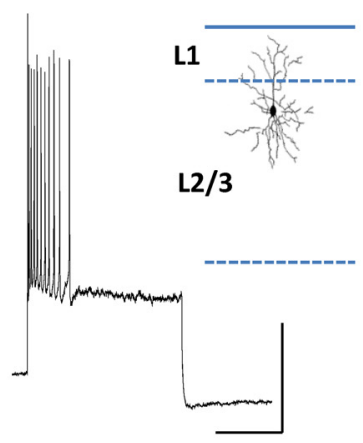

C
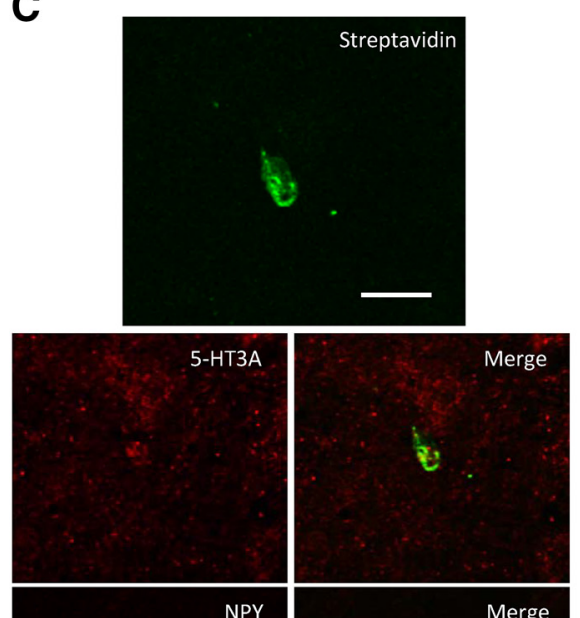

NPY
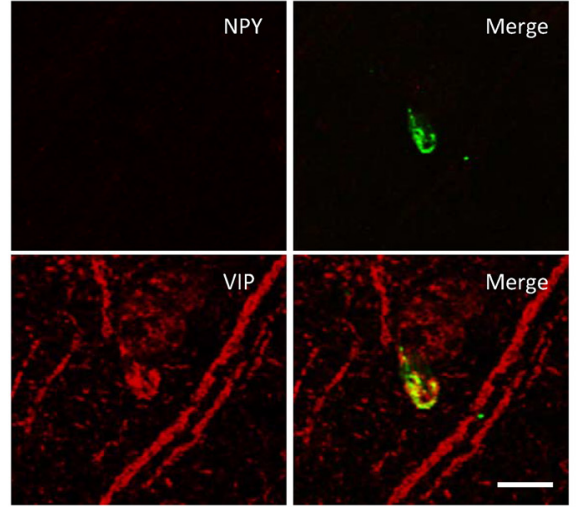

D

B
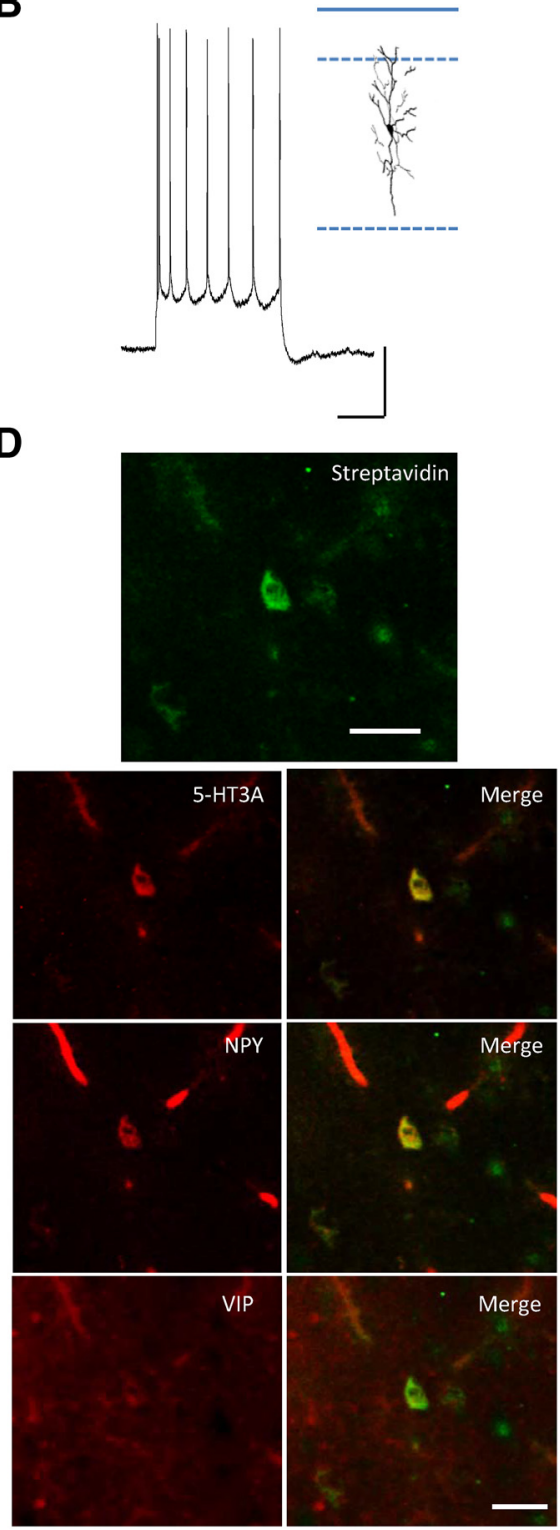

Figure 5. Interneuron subtypes involved are immunopositive for NPY or VIP. $\boldsymbol{A}$, Example of response to step current injection $(0.5 \mathrm{nA}, 0.2 \mathrm{~s})$ for a FA interneuron in layer 2 of parietal cortex. Inset shows biocytin reconstruction. $\boldsymbol{B}$, Example of response to step current injection $(0.2 \mathrm{nA}, 0.2 \mathrm{~s})$ for a SA interneuron in layer 2 of parietal cortex. Inset shows biocytin reconstruction. C, Immunocytochemical characterization of an FA neuron from layer 2 parietal cortex demonstrating the electrophysiological properties during delta and SpW shown in Figure $6 B$. Confirmation of cell recorded from was performed with biocytin fill and post hoc fluorescent streptavidin antibody visualization. Antibodies to $5-\mathrm{HT}_{3 \mathrm{~A}}$ receptors showed weak immunopositivity, whereas NPY and VIP immunofluorescence were negative and strongly positive respectively. $\boldsymbol{D}$, Immunocytochemical characterization of an SA neuron from layer 2 parietal cortex demonstrating the electrophysiological properties during delta and SpW shown in Figure $6 C$. Confirmation of cell recorded from was performed with biocytin fill and post hoc fluorescent streptavidin antibody visualization. Antibodies to $5-\mathrm{HT}_{3 \mathrm{~A}}$ receptors showed strong immunopositivity, whereas NPY and VIP immunofluorescence were strongly positive and negative respectively. Scale bars: $\boldsymbol{A}, \boldsymbol{B}, 20 \mathrm{mV}, 50 \mathrm{~ms} ; \boldsymbol{C}, \boldsymbol{D}, 20 \mu \mathrm{m}$.

was accompanied by a modest but significant increase in mean peak EPSP amplitude $(6.7 \pm 0.3 \mathrm{mV}$ vs $5.7 \pm 0.1 \mathrm{mV}, p<0.05)$ but a large, tonic hyperpolarization. These contrasting changes in action potential outputs and tonic membrane potential changes in FA and SA neurons were investigated further.

$\mathrm{SpW}$ generation required NPY-containing interneuron quiescence-associated disinhibition of VIP-containing interneurons

The transition from control delta rhythms to $\mathrm{SpW}$ with bath application of dTC was preceded by overt, tonic hyperpolariza- tion of NPY-immunopositive SA neurons. Hyperpolarization began $2 \mathrm{~min}$ after dTC application with a significant hyperpolarization observed and maintained 6 min after the application of dTC $(p<$ $0.05)$. Mean peak resting membrane potential change was $-21 \pm 4 \%, n=4, p<$ 0.05 . The opposite effect was seen in VIPimmunopositive FA neurons. With a delay of 6 min following SA neuron hyperpolarization onset and a significant depolarization observed and maintained from $12 \min (p<0.05)$, FA neurons depolarized by a steady-state maximum of $+21 \pm 6 \%, n=5, p<0.05$. At times of 6 and 8 min following application of dTC a significant difference was seen between the membrane potential change in VIPimmunopositive interneurons and NPYimmunopositive interneurons (Fig. 7Ai). Although no significant change from predTC application times was seen in VIPimmunopositive neurons $(p>0.05)$, a significant hyperpolarization of NPYimmunopositive neurons was seen $(p<$ $0.05)$. This delay between the two membrane potential changes suggested a link between the NPY-immunopositive SA neuron effect and the VIP-immunopositive FA neuron effect. The reduction in NPYimmunopositive SA cell outputs and de novo generation of VIP-immunopositive FA neuron outputs on SpW generation was associated with an overt change in the profile of fast and slow inhibition in superficial layer RS neurons. Integrating fast and slow inhibitory components (separated by differential filtering of membrane potential at $-30 \mathrm{mV}$ ) and comparing between control delta periods and SpW events revealed a $71 \pm 14 \%$ reduction in fast inhibition and a $232 \pm 57 \%$ increase in slow inhibition ( $n=54$ events, $p<0.05$; Fig. 7 Aii,Aiii). Interestingly the overall integral of inhibition was greater during epileptiform SpW when compared with control delta periods in superficial RS neurons (see Discussion).

To try to quantify the roles played by each of the two peptides NPY and VIP, we compared the incidence of $\mathrm{SpW}$ in the dTC model alone, and in the presence of antagonists for NPY receptors and VIP receptors. Blockade of NPY Y1 receptors with BMS193885 application before the application of dTC generated a different profile of $\mathrm{SpW}$ to dTC alone. A rapid development of $\mathrm{SpW}$ was seen over the first $\sim 20$ min of dTC application (Fig. 7Bi) before stabilizing. In contrast, the dTC alone-induced SpW incidence did not peak until 40 min after drug addition. Peak mean SpW incidence with combined dTC and NPY1 receptor blockade was actually greater than with the dTC model, but pooled values were not significantly different at a time point of $45 \mathrm{~min}$ (dTC $10.5 \pm 5.0 \mathrm{~min}^{-1}$ vs dTC + BMS $16.1 \pm 1.9 \min ^{-1}, n=5, p<0.05$; Fig. 7 Bii). No 
A

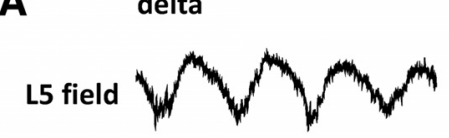

B VIP+ve
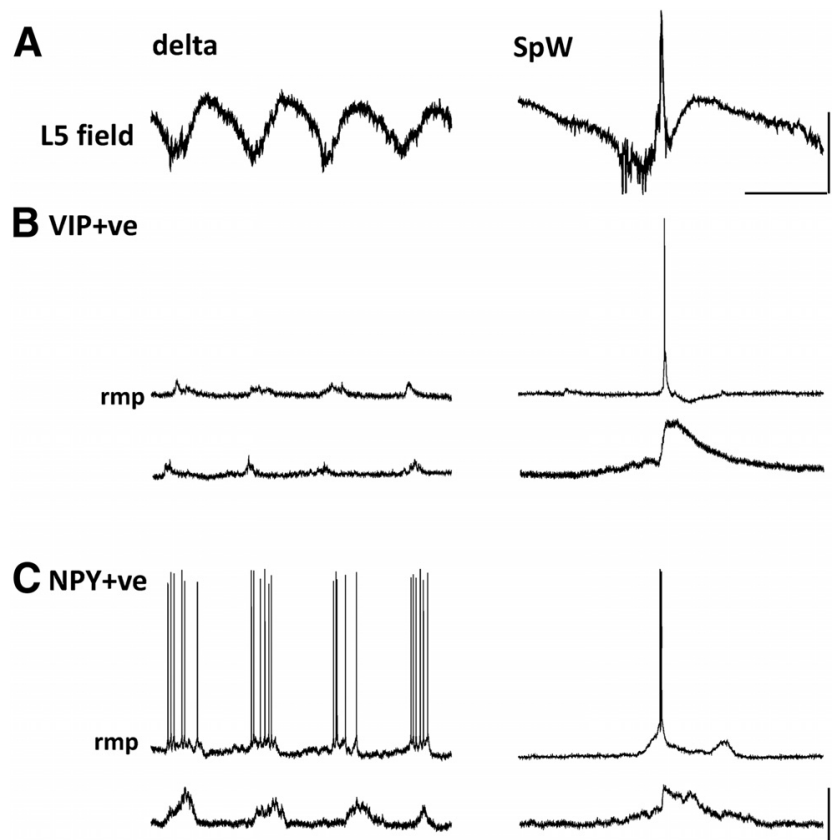

Figure 6. VIP- and NPY-immunopositive superficial neocortical interneuron outputs are differentially affected during $\mathrm{SpW}$ generation. Recordings from two subtypes of superficial layer neurons resembling those previously shown to be 5 - $\mathrm{HT}_{3}$-immunopositive (Lee et al., 2010) revealed opposing changes in outputs associated with SpW generation. $\boldsymbol{A}$, Example field potentials from layer 5 parietal cortex during control delta rhythms and SpW discharges. $\boldsymbol{B}$, Left, Example behavior of an FA neuron during control delta activity at resting membrane potential $(\mathrm{rmp}=-72 \mathrm{mV})$ and at $-80 \mathrm{mV}$ (lower trace). Note the complete absence of action potential generation despite delta frequency compound EPSP inputs. Right, Example behavior of the same neuron during SpW generation. The spike component of the field SpW was accompanied by action potential generation in the $\mathrm{FA}$ neuron at $\mathrm{rmp}(-54 \mathrm{mV}$; Fig. $7 \mathrm{~A})$ and a significantly increased EPSP input when recorded at $-80 \mathrm{mV}$ (bottom trace; see Results). C, Left, Example behavior of an $\mathrm{SA}$ neuron during control delta activity at resting membrane potential ( $\mathrm{rmp}=$ $-60 \mathrm{mV}$ ) and at $-80 \mathrm{mV}$ (bottom trace). Note the vigorous, delta locked action potential burst generation despite receipt of only weak, delta frequency compound EPSP inputs. Right, Example behavior of the same neuron during SpW generation. The SA neuron generated only 1-2 action potentials at the peak of the spike component of the field $\mathrm{SpW}$, and at no other time at rmp ( $-74 \mathrm{mV}$; Fig. $7 A)$ despite a modestly increased EPSP input when recorded at $-80 \mathrm{mV}$ (bottom trace). Scale bars: $A, 0.25 \mathrm{mV}, 400 \mathrm{~ms} ; \boldsymbol{B}, \boldsymbol{C}, 20 \mathrm{mV}, 400 \mathrm{~ms}$.

change in the maximal mean amplitude of local field potential $\mathrm{SpW}$ measures was seen between these two conditions (Fig. 7Biii).

In contrast, application of the VIP receptor antagonist [D-pCl-Phe6, Leu17]-VIP before the application of dTC caused a dramatic retardation in the development of SpW activity. Attempts to generate SpW with dTC application in the presence of VIP receptor antagonism produced a significantly lower incidence of SpW compared with dTC alone at the 45 min time point (dTC alone $10.5 \pm 5.0 \mathrm{~min}^{-1}$ vs dTC + VIP antagonism $2.6 \pm 0.5$ $\left.\min ^{-1}, n=5, p<0.05\right)$. In addition, the few SpW discharges that were observed were smaller in terms of local field potential peak amplitudes (dTC $0.39 \pm 0.08 \mathrm{mV}$ vs dTC + VIP antagonism $0.04 \pm 0.01 \mathrm{mV}, p<0.05$; Fig. 7Biii). The application of the VIP receptor antagonist alone produced no SpW events at all $(n=7)$.

dTC affects a number of different synaptic and intrinsic conductances in neurons (see Discussion) so to further investigate the role played by these two peptidergic systems in SpW generation we applied an NPY receptor antagonist alone or jointly with a VIP receptor agonist directly to control, delta rhythmgenerating slices in the absence of dTC. In VIP-immunopositive neurons addition of $10 \mu \mathrm{M}$ BMS193885 caused a depolarization of $17 \pm 2 \%$ from control mean membrane potential; a value not significantly different from that seen when NPY-immunopositive SA neuron output was reduced by dTC ( $p<0.05, n=5$; Fig. 7Ai). This direct blockade of $Y 1$ receptor responses, and the concurrent increase in VIP-immunopositive neuron activity produced SpW events of significantly smaller peak-to-peak magnitude but higher incidence than the dTC model (Fig. 7C; dTC alone vs BMS193885 alone $p<0.05, n=5$ ). Enhancing the effects of any increased released VIP in the tissue in these conditions was attempted by bath coapplication of the VIP peptide itself. This also caused the generation of significantly smaller SpW events but also a much larger (near fivefold) increase in incidence (dTC alone vs BMS193885 plus VIP, $p<0.05, n=5$ ).

\section{Discussion}

The present data demonstrate that both sporadic and continuous slow SpW discharges, a feature of many epilepsy syndromes, can be generated by local circuitry within neocortex in the absence of thalamic involvement. This manifestation of SpW appeared to be dependent on the pre-existence of ongoing delta rhythms and, for the most part, represented a pathological deviation from preexisting network interactions: First, the wave, or "dome" component of the SpW was seen as a larger, more intense period of the delta rhythm in the sense that it too was characterized by a protracted, repetitive burst of output, riding on a large, long EPSP in layer 5 IB neurons. It should be noted that larger, slower delta rhythms alone are a feature of some epilepsies (Tao et al., 2011). Second, the spike, or "dart" component of the SpW was associated with a switch from sparse single spiking in layer 2/3 RS principal cells to intense, brief burst discharges. In control, delta rhythm conditions the activity patterns in infra- and supragranular layers were tightly linked via a weak but significant ascending excitatory pathway from layer 5 to layers $2 / 3$ and a strong reciprocal descending pathway (Lefort et al., 2009; Carracedo et al., 2013). However, in the computational model used here the origin of these intense bursts on each SpW was predicted to be mediated also by recurrent excitation within layers $2 / 3$ (see below).

The essential nature of a pre-existing delta rhythm for these type of epileptiform events was demonstrated in Figure 3, but is also evident from patient studies and other, previous animal models. Discrete syndromes involving intense, continuous SpW precipitated by sleep/wake transitions are a feature of some epilepsy pathologies (Yasuhara et al., 1991). A correlation between these epileptiform discharges and delta rhythms has also been reported for decreased $\mathrm{GABA}_{\mathrm{A}}$ receptor function-mediated seizures in animals with altered nicotinic receptor composition (Klaassen et al., 2006). In vitro experiments revealed this relationship to be absolute: absence of delta rhythms excluded the model presented here from generating $\mathrm{SpW}$. However, the situation was much less clear-cut (though statistically significant) in vivo. This may represent the near-continuous expression of delta rhythms regardless of behavioral state: Delta rhythms are a key mechanism involved in some forms of cognition in the awake state (Schroeder and Lakatos, 2009). In addition, human genetic studies have shown that SpW-type epilepsies are associated with enhanced NMDA receptor function genetically (Lemke et al., 2013) and the typical age of presentation for severe SpW-related epilepsies ( 3-9 years) correlates with a developmental period where both delta rhythms and NMDA receptor function are elevated with respect to adulthood. NMDA receptor function is vital for delta rhythm generation (Carracedo et al., 2013). 

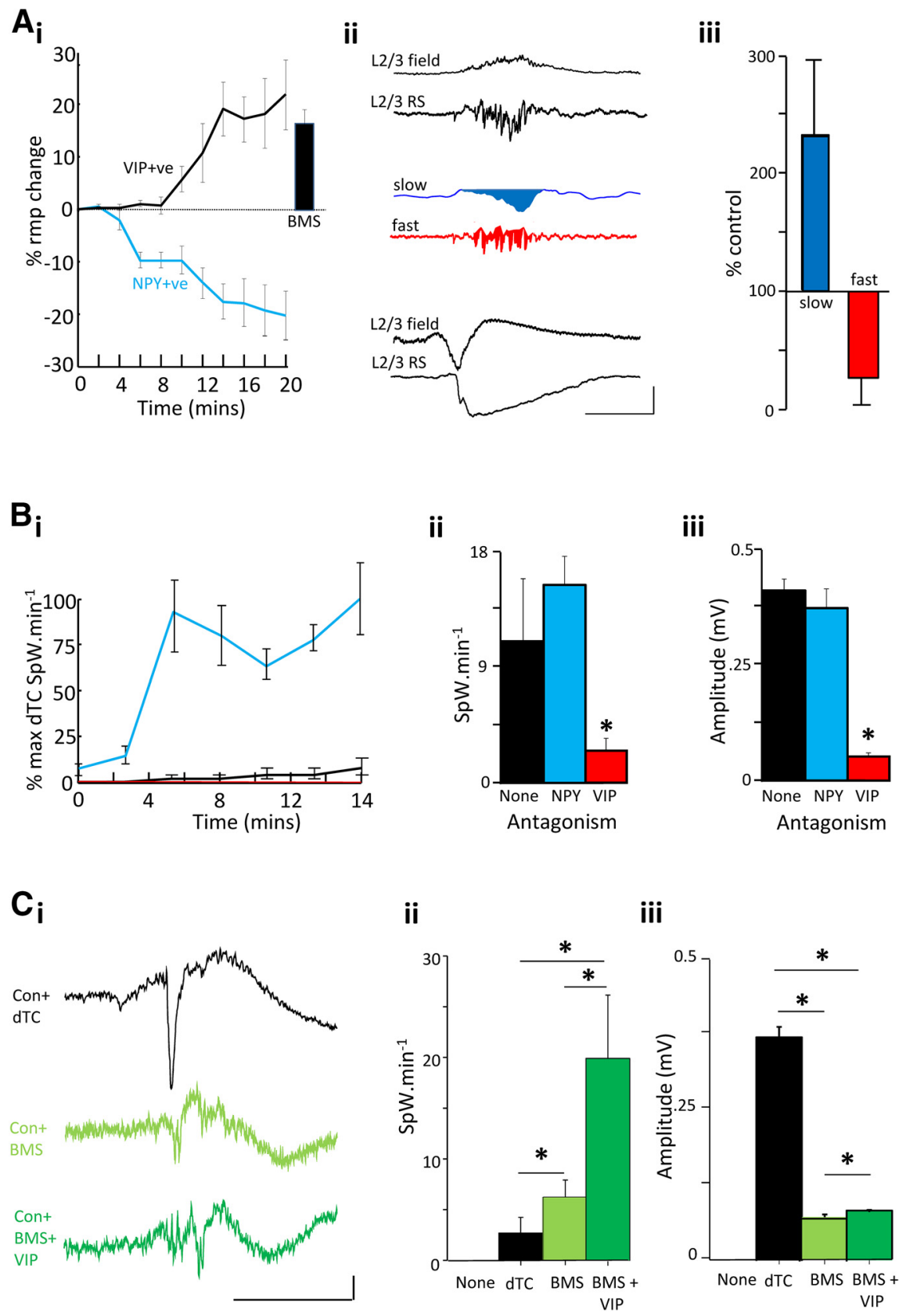

Figure 7. Both reduced NPY-mediated inhibition and enhanced VIP-mediated inhibition are required for SpW generation. Ai, Mean ( \pm SEM) resting membrane potential changes preceeding SpW generation following bath application of tubocurarine (time $=0$ ). Tonic hyperpolarization of NPY-immunopositive, SA neurons (blue line; $n=5$ ) preceded tonic depolarization of VIP-immunopositive, FA interneurons (black line; $n=5$ ). To assess the role of reduced NPY release in the FA depolarization the NPY receptor antagonist BMS193885 alone (in the absence of tubocurarine) was bath applied to control delta rhythms while recording from FA neurons. Black bar shown mean ( \pm SEM,$n=5$ ) depolarization caused thereby. Aii, Example traces showing the change from predominantly fast to slow inhibition accompanying sharp wave generation. Top two traces show a single control delta period (Top = field) and corresponding IPSP profile (L2/3 regular spiking (RS) cell, $-30 \mathrm{mV}$ ). Middle two traces show an example of the output from the filtering process used to derive estimates of fast decaying (red) and slow decaying (blue) inhibition from the intracellular recordings. Botom two traces show a single spontaneous SpW discharge (top $=$ field) and corresponding IPSP profile from the same cell. Aiii, Mean ( $n=16$ events) change in contribution of fast decaying and slow decaying inhibition to the compound IPSP comparing control delta to SpW. Bi, Mean incidence in events ( $n=5-7)$ for the first 16 min following tubocurarine bath administration alone (black line) or with coadministered NPY receptor antagonism (BMS193885; blue line), or with VIP receptor antagonism ([D-p-Cl-Phe6, Leu17]-VIP; red line). Bii, Biii, Mean characteristics of SpW incidence and maximal field potential amplitude in the first hour following tubocurarine (black bars) or tubocurarine and the above NPY or VIP receptor antagonists. Note VIP antagonism significantly attenuated both incidence and amplitude of SpW discharges, ${ }^{*} p<0.05$. Ci, Example traces showing typical SpW types generated by dTC alone, BMS193885 alone or BMS193885 plus VIP. Scale bars $50 \mu V$, 1s. Cii, Ciii, Quantification of the effects of NPY antagonism alone or in the presence of VIP with dTC-induced SpW activity.
Care has to be taken in interpreting the present data with respect to other animal models however. The majority of genetic models generate fast SpW (5-9 Hz; Sasa and Yamada, 1988; Marescaux et al., 1992; Strohl et al., 2007; Pearce and Scharfman, 2014) which may be thalamocortical in origin; being considered as deranged spindle-like activity (Kostopoulos, 2000). This may also in part explain the lack of overall correlation between these fast SpW and slow-wave sleep: fast events in rat are associated with arousal predominantly, though reports of increased incidence on stimulation of sleep-promoting areas appears to counter this (Suntsova et al., 2009). Fast SpW are also seen in patients and, again, are not necessarily associated with sleep. However, this type of epileptiform discharge is rather rare (0.5-1\% of patients presenting with SpW; Hughes, 1980). In general, the majority of patients exhibiting SpW demonstrate slower frequencies ranging from $\sim 3 \mathrm{~Hz}$ down to sub $1 \mathrm{~Hz}$ levels, and even isolated single SpW as a form of interictal-like discharge (Niedermeyer, 2005).

The most overt finding of the present study in terms of this model of slow SpWrelated pathology was the transition from sparse single spikes to intense bursting in superficial layer RS neurons. The computational model predicted a dual cause for this change in behavior: a failure of $\mathrm{GABA}_{\mathrm{A}}$ receptor-mediated inhibition and an elevation of recurrent excitation in superficial layers. The reduced inhibition appeared to be primarily related to decreased output from $5-\mathrm{HT}_{3}$ and NPYimmunopositive interneurons in the present study. However, another subtype of interneuron, immunopositive for VIP, was found to have an increased output. These two interneuron subtypes appear very similar to caudal ganglionic eminence (CGE)-derived interneurons reported previously. Lee et al. (2010) provide a detailed and elegant description of 5 - $\mathrm{HT}_{3}$-immunopositive superficial neocortical interneurons. The fast adapting and slow adapting cells recorded here have electrophysiological and cytoarchitectonic properties almost identical to the "FAD" and "bNA" subtypes, respectively (Lee et al., 2010). In general, CGE-derived interneurons have been implicated in epilepsy previously (Kusuzawa et al., 2012). In particular, genetic manipulation of CGE-derived interneuron development that reduces CGE interneurons in favor of MGE-derived interneurons results in a resistance to some epileptogenic stimuli (Lodato et al., 2011). 
The pharmacological profile of slow SpW-induction tested here strongly suggested a role of antagonism of $\mathrm{nAchR}$ and $5-\mathrm{HT}_{3}$ receptors (Fig. 4). The location and immunocytochemical profile of the two interneuron subtypes linked to SpW here indicate neurons that receive both serotoninergic and nicotinergic excitation (Porter et al., 1999; Férézou et al., 2002), suggesting that the pharmacological models of SpW were selectively targeting these cells. The connection to nicotinic receptors links these cells to a great deal of prior work on specific epilepsy syndromes (Fonck et al., 2005), and a less well precedented link between SpW epilepsies and serotonin neuromodulation (Ohno et al., 2010). However, the seemingly differential role of the two interneuron subtypes studies does not begin to make sense unless their different peptidergic components are taken into account.

In the model used here the generation of SpW appeared to be most closely correlated with loss of NPY-immunopositive interneuron function. This could occur via hyperpolarization secondary to loss of $\mathrm{nAchR}$ - and $5-\mathrm{HT}_{3}$-mediated excitation through tubocurarine application (Figs. 4, 7). However, tubocurarine acts on many neuron-wide excitatory control mechanisms such as calcium-activated potassium channels (Smart, 1987). To control for this we showed that SpW could also occur directly through blockade of Y1 receptors alone (Fig. 7). NPY-mediated neuromodulation is closely related to epileptiform activity: NPY expression levels are disrupted in SpW-generating epilepsy models (Chafetz et al., 1995); Acute NPY level enhancement suppresses absence seizures (Morris et al., 2007); valproate, a first choice treatment for SpW-related epilepsies increases NPY levels in the brain (Brill et al., 2006; Elms et al., 2013). In physiological conditions NPY serves a dual purpose in neocortex in that it both boosts $\mathrm{GABA}_{\mathrm{A}}$ receptor-mediated postsynaptic responses and reduces fast synaptic excitation (Bacci et al., 2002). In other words, merely reducing NPY levels as seen here, may provide each of the conditions predicted by the computational model as essential for SpW generation. However, the relationship between NPY-immunopositive interneurons and VIP-immunopositive interneurons provides a pathway for additional pathology.

VIP-immunopositive interneurons are preferentially active during sensory input (Lee et al., 2013), perhaps explaining why they were completely silent during control delta rhythms in the cortex-only preparation used here. However, when active they have been shown to be strongly disinhibitory in that they mainly act by reducing output from other dendrite-targeting interneurons (Pi et al., 2013). VIP levels are elevated in various forms of human epilepsy (Ko et al., 1991; de Lanerolle et al., 1995) suggesting a potentially causal role given that manipulation of interneuronal development in favor of parvalbumin-immunopositive neurons at the expense of VIP-immunopositive neurons imparts seizureresistance (Lodato et al., 2011). Interestingly, VIP levels are differentially modulated by seizures compared with NPY levels and are closely related to nAchR neuromodulation (Ko et al., 1991; Marksteiner et al., 1989).

The large-scale consequence of transition from delta rhythms to $\mathrm{SpW}$ was not per se a loss of inhibition, rather a change in the balance from dominant fast inhibition to dominant slow inhibition (Fig. 7). It is not yet known whether VIP-immunopositive neurons provide a specific source of $\mathrm{GABA}_{\mathrm{B}}$-receptor mediated inhibition in neocortex. Although they have been shown to generate slow inhibition in terms of postsynaptic kinetics (Tamás et al., 2003), only a small proportion of VIP-immunopositive interneurons are associated with the classical source of slow inhibition; the $\mathrm{GABA}_{\mathrm{B}}$ receptor (McDonald et al., 2004). However, a strong interrelationship between VIP postsynaptic effects and
$\mathrm{GABA}_{\mathrm{B}}$ receptor function has been noted. In general, however, levels of slow inhibition are critical for the control of superficial neocortical function (Oláh et al., 2007; Craig and McBain, 2014). It is interesting to note the observed role for slow inhibition in SpW generation seen here appears to parallel that proposed for the thalamic SpW generator (Destexhe, 1998). Thus, in vivo a synergy may occur between pathological manifestation of $\mathrm{GABA}_{\mathrm{B}}$ versus $\mathrm{GABA}_{\mathrm{A}}$ receptor-mediated inhibition in thalamus and neocortex as these two areas are strongly coupled during normal slow brain rhythms (Crunelli and Hughes, 2010).

In summary the present findings demonstrate a pivotal role for NPY-immunopositive interneurons in modulating cortical excitability. A failure to generate sufficient output from this neuron subclass has multiple knock-on effects, all acting together to generate $\mathrm{SpW}$. The data suggest that reduced $\mathrm{GABA}_{\mathrm{A}}$ receptormediated synaptic inhibition from NPY-immunopositive interneurons onto principal cells directly increases superficial layer excitability. This appeared to be generated by a reduced release of NPY, thus ablating the normal potentiation of synaptic inhibition and attenuation of synaptic excitation mediated by this neuropeptide. Finally, a loss of tonic, NPY-mediated inhibition of VIP-immunopositive neurons activates this neuron subclass. The resulting disinhibition of other interneuron types serves to further enhance superficial cortical excitability. The ability to generate SpW with NPY Y1 receptor antagonism alone, coupled with the near-complete abolition of SpW with VIP receptor antagonism suggests a potential novel therapeutic approach to epilepsy therapy using altered balance of peptidergic inhibition.

\section{References}

Angeleri F, Berbonzi P, Ferroni A (1968) A statistical study of the amount of diffuse synchronous spike and wave activity during nocturnal polygraphic recording in epileptics. Electroencephalogr Clin Neurophysiol 25:85-86. Medline

Archer JS, Warren AE, Stagnitti MR, Masterton RA, Abbott DF, Jackson GD (2014) Lennox-Gastaut syndrome and phenotype: secondary network epilepsies. Epilepsia 55:1245-1254. CrossRef Medline

Bacci A, Huguenard JR, Prince DA (2002) Differential modulation of synaptic transmission by neuropeptide $\mathrm{Y}$ in rat neocortical neurons. Proc Natl Acad Sci U S A 99:17125-17130. CrossRef Medline

Bölsterli Heinzle BK, Fattinger S, Kurth S, Lebourgeois MK, Ringli M, Bast T, Critelli H, Schmitt B, Huber R (2014) Spike wave location and density disturb sleep slow waves in patients with CSWS (continuous spike waves during sleep). Epilepsia 55:584-591. CrossRef Medline

Brill J, Lee M, Zhao S, Fernald RD, Huguenard JR (2006) Chronic valproic acid treatment triggers increased neuropeptide $\mathrm{Y}$ expression and signaling in rat nucleus reticularis thalami. J Neurosci 26:6813-6822. CrossRef Medline

Carracedo LM, Kjeldsen H, Cunnington L, Jenkins A, Schofield I, Cunningham MO, Davies CH, Traub RD, Whittington MA (2013) A neocortical delta rhythm facilitates reciprocal interlaminar interactions via nested theta rhythms. J Neurosci 33:10750-10761. CrossRef Medline

Carvill GL, Regan BM, Yendle SC, O’Roak BJ, Lozovaya N, Bruneau N, Burnashev N, Khan A, Cook J, Geraghty E, Sadleir LG, Turner SJ, Tsai MH, Webster R, Ouvrier R, Damiano JA, Berkovic SF, Shendure J, Hildebrand MS, Szepetowski P, et al. (2013) GRIN2A mutations cause epilepsyaphasia spectrum disorders. Nat Genet 45:1073-1076. CrossRef Medline

Chafetz RS, Nahm WK, Noebels JL (1995) Aberrant expression of neuropeptide $\mathrm{Y}$ in hippocampal mossy fibers in the absence of local cell injury following the onset of spike-wave synchronization. Brain Res Mol Brain Res 31:111-121. CrossRef Medline

Chhun S, Troude P, Villeneuve N, Soufflet C, Napuri S, Motte J, Pouplard F, Alberti C, Helfen S, Pons G, Dulac O, Chiron C (2011) A prospective open-labeled trial with levetiracetam in pediatric epilepsy syndromes: continuous spikes and waves during sleep is definitely a target. Seizure 20:320-325. CrossRef Medline

Craig MT, McBain CJ (2014) The emerging role of $\mathrm{GABA}_{\mathrm{B}}$ receptors as 
regulators of network dynamics: fast actions from a "slow" receptor? Curr Opin Neurobiol 26:15-21. CrossRef Medline

Crunelli V, Hughes SW (2010) The slow $(<1 \mathrm{~Hz})$ rhythm of non-REM sleep: a dialogue between three cardinal oscillators. Nat Neurosci 13: 9-17. CrossRef Medline

Crunelli V, Leresche N (2002) Childhood absence epilepsy: genes, channels, neurons and networks. Nat Rev Neurosci 3:371-382. CrossRef Medline

Dajas F, Gaztelu JM, Zavalla CR, Macadar O, García-Austt E (1983) Effects of intraventricular curarimimetics on hippocampal electrical activity. Exp Neurol 79:160-167. CrossRef Medline

Danober L, Depaulis A, Marescaux C, Vergnes M (1993) Effects of cholinergic drugs on genetic absence seizures in rats. Eur J Pharmacol 234:263268. CrossRef Medline

de Lanerolle NC, Gunel M, Sundaresan S, Shen MY, Brines ML, Spencer DD (1995) Vasoactive intestinal polypeptide and its receptor changes in human temporal lobe epilepsy. Brain Res 686:182-193. CrossRef Medline

Destexhe A (1998) Spike-and-wave oscillations based on the properties of $\mathrm{GABA}_{\mathrm{B}}$ receptors. J Neurosci 18:9099-9111. Medline

Destexhe A, McCormick DA, Sejnowski TJ (1999) Thalamic and thalamocortical mechanisms underlying $3 \mathrm{~Hz}$ spike-and-wave discharges. Prog Brain Res 121:289-307. CrossRef Medline

Elms J, Powell KL, van Raay L, Dedeurwaerdere S, O’Brien TJ, Morris MJ (2013) Long-term valproate treatment increases brain neuropeptide $Y$ expression and decreases seizure expression in a genetic rat model of absence epilepsy. PLoS One 8:e73505. CrossRef Medline

Férézou I, Cauli B, Hill EL, Rossier J, Hamel E, Lambolez B (2002) 5- $\mathrm{HT}_{3}$ receptors mediate serotonergic fast synaptic excitation of neocortical vasoactive intestinal peptide/cholecystokinin interneurons. J Neurosci 22: 7389-7397. Medline

Fisher RS, Prince DA (1977) Spike-wave rhythms in cat cortex induced by parenteral penicillin: 1. Electroencephalographic features. Electroencephalogr Clin Neurophysiol 42:608-624. CrossRef Medline

Fonck C, Cohen BN, Nashmi R, Whiteaker P, Wagenaar DA, RodriguesPinguet N, Deshpande P, McKinney S, Kwoh S, Munoz J, Labarca C, Collins AC, Marks MJ, Lester HA (2005) Novel seizure phenotype and sleep disruptions in knock-in mice with hypersensitive alpha $4^{\star}$ nicotinic receptors. J Neurosci 25:11396-11411. CrossRef Medline

Gotti C, Balestra B, Moretti M, Rovati GE, Maggi L, Rossoni G, Berti F, Villa L, Pallavicini M, Clementi F (1998) 4-Oxystilbene compounds are selective ligands for neuronal nicotinic alpha-bungarotoxin receptors. $\mathrm{Br} \mathrm{J}$ Pharmacol 124:1197-1206. CrossRef Medline

Halai R, Clark RJ, Nevin ST, Jensen JE, Adams DJ, Craik DJ (2009) Scanning mutagenesis of alpha-conotoxin $\mathrm{Vc} 1.1$ reveals residues crucial for activity at the alpha9alpha10 nicotinic acetylcholine receptor. J Biol Chem 284: 20275-20284. CrossRef Medline

Hughes JR (1980) Two forms of the 6/sec spike and wave complex. Electroencephalogr Clin Neurophysiol 48:535-550. CrossRef Medline

Hughes JR (2011) A review of the relationships between Landau-Kleffner syndrome, electrical status epilepticus during sleep, and continuous spike-waves during sleep. Epilepsy Behav 20:247-253. CrossRef Medline

Huntsman MM, Porcello DM, Homanics GE, DeLorey TM, Huguenard JR (1999) Reciprocal inhibitory connections and network synchrony in the mammalian thalamus. Science 283:541-543. CrossRef Medline

Ioannides AA, Kostopoulos GK, Liu L, Fenwick PB (2009) MEG identifies dorsal medial brain activations during sleep. Neuroimage 44:455-468. CrossRef Medline

Klaassen A, Glykys J, Maguire J, Labarca C, Mody I, Boulter J (2006) Seizures and enhanced cortical GABAergic inhibition in two mouse models of human autosomal dominant nocturnal frontal lobe epilepsy. Proc Natl Acad Sci U S A 103:19152-19157. CrossRef Medline

Kluger G, Böhm I, Laub MC, Waldenmaier C (1996) Epilepsy and fragile X gene mutations. Pediatr Neurol 15:358-360. CrossRef Medline

Ko FJ, Chiang CH, Liu WJ, Chiang W (1991) Somatostatin, substance P, prolactin and vasoactive intestinal peptide levels in serum and cerebrospinal fluid of children with seizure disorders. Gaoxiong Yi Xue Ke Xue Za Zhi 7:391-397. Medline

Kostopoulos GK (2000) Spike-and-wave discharges of absence seizures as a transformation of sleep spindles: the continuing development of a hypothesis. Clin Neurophysiol 111:S27-S38. CrossRef Medline

Kusuzawa S, Honda T, Fukata Y, Fukata M, Kanatani S, Tanaka DH, Nakajima K (2012) Leucine-rich glioma inactivated 1 (Lgi1), an epilepsyrelated secreted protein, has a nuclear localization signal and localizes to both the cytoplasm and the nucleus of the caudal ganglionic eminence neurons. Eur J Neurosci 36:2284-2292. CrossRef Medline

Lacey CJ, Bryant A, Brill J, Huguenard JR (2012) Enhanced NMDA receptor-dependent thalamic excitation and network oscillations in stargazer mice. J Neurosci 32:11067-11081. CrossRef Medline

Lee SE, Lee J, Latchoumane C, Lee B, Oh SJ, Saud ZA, Park C, Sun N, Cheong E, Chen CC, Choi EJ, Lee CJ, Shin HS (2014) Rebound burst firing in the reticular thalamus is not essential for pharmacological absence seizures in mice. Proc Natl Acad Sci U S A 111:11828-11833. CrossRef Medline

Lee S, Hjerling-Leffler J, Zagha E, Fishell G, Rudy B (2010) The largest group of superficial neocortical GABAergic interneurons expresses ionotropic serotonin receptors. J Neurosci 30:16796-16808. CrossRef Medline

Lee S, Kruglikov I, Huang ZJ, Fishell G, Rudy B (2013) A disinhibitory circuit mediates motor integration in the somatosensory cortex. Nat Neurosci 16:1662-1670. CrossRef Medline

Lefort S, Tomm C, Floyd Sarria JC, Petersen CC (2009) The excitatory neuronal network of the $\mathrm{C} 2$ barrel column in mouse primary somatosensory cortex. Neuron 61:301-316. CrossRef Medline

Lemke JR, Lal D, Reinthaler EM, Steiner I, Nothnagel M, Alber M, Geider K, Laube B, Schwake M, Finsterwalder K, Franke A, Schilhabel M, Jähn JA, Muhle H, Boor R, Van Paesschen W, Caraballo R, Fejerman N, Weckhuysen S, De Jonghe P, et al. (2013) Mutations in GRIN2A cause idiopathic focal epilepsy with rolandic spikes. Nat Genet 45:1067-1072. CrossRef Medline

Lennox WG, Davis JP (1950) Clinical correlates of the fast and the slow spike-wave electroencephalogram. Pediatrics 5:626-644. Medline

Ligot N, Archambaud F, Trotta N, Goldman S, Van Bogaert P, Chiron C, De Tiège $X$ (2014) Default mode network hypometabolism in epileptic encephalopathies with CSWS. Epilepsy Res 108: 861-71. CrossRef Medline

Lodato S, Tomassy GS, De Leonibus E, Uzcategui YG, Andolfi G, Armentano M, Touzot A, Gaztelu JM, Arlotta P, Menendez de la Prida L, Studer M (2011) Loss of COUP-TFI alters the balance between caudal ganglionic eminence- and medial ganglionic eminence-derived cortical interneurons and results in resistance to epilepsy. J Neurosci 31:4650-4662. CrossRef Medline

Luo S, Kulak JM, Cartier GE, Jacobsen RB, Yoshikami D, Olivera BM, McIntosh JM (1998) $\alpha$-Conotoxin AuIB selectively blocks $\alpha 3 \beta 4$ nicotinic acetylcholine receptors and nicotine-evoked norepinephrine release. J Neurosci 18:8571-8579. Medline

Luo S, Nguyen TA, Cartier GE, Olivera BM, Yoshikami D, McIntosh JM (1999) Single-residue alteration in alpha-conotoxin PnIA switches its nAChR subtype selectivity. Biochemistry 38:14542-14548. CrossRef Medline

Marescaux C, Vergnes M, Depaulis A (1992) Genetic absence epilepsy in rats from Strasbourg: a review. J Neural Transm Suppl 35:37-69. Medline

Marksteiner J, Sperk G, Maas D (1989) Differential increases in brain levels of neuropeptide $\mathrm{Y}$ and vasoactive intestinal polypeptide after kainic acidinduced seizures in the rat. Naunyn Schmiedebergs Arch Pharmacol 339: 173-177. Medline

McDonald AJ, Mascagni F, Muller JF (2004) Immunocytochemical localization of GABABR1 receptor subunits in the basolateral amygdala. Brain Res 1018:147-158. CrossRef Medline

Medeiros LL, Yasuda C, Schmutzler KM, Guerreiro MM (2010) Rolandic discharges: clinico-neurophysiological correlation. Clin Neurophysiol 121:1740-1743. CrossRef Medline

Morris MJ, Gannan E, Stroud LM, Beck-Sickinger AG, O’Brien TJ (2007) Neuropeptide $Y$ suppresses absence seizures in a genetic rat model primarily through effects on Y receptors. Eur J Neurosci 25:1136-1143. CrossRef Medline

Niedermeyer E (2005) Abnormal EEG patterns: epileptic and paroxysmal. In: Electroencephalograph:basic principles, clinical applications and related fields, (Niedermeyer E, Lopez da Silva F, eds), pp 255-280. Philadelphia: Lippincott Williams and Wilkins.

Ohno Y, Sofue N, Imaoku T, Morishita E, Kumafuji K, Sasa M, Serikawa T (2010) Serotonergic modulation of absence-like seizures in groggy rats: a novel rat model of absence epilepsy. J Pharmacol Sci 114:99-105. CrossRef Medline

Oláh S, Komlósi G, Szabadics J, Varga C, Tóth E, Barzó P, Tamás G (2007) Output of neurogliaform cells to various neuron types in the human and rat cerebral cortex. Front Neural Circuits 1:4. CrossRef Medline

Otis TS, De Koninck Y, Mody I (1993) Characterization of synaptically elic- 
ited $\mathrm{GABA}_{\mathrm{B}}$ responses using patch clamp recordings in rat hippocampal slices. J Physiol 463:391-407. CrossRef Medline

Pearce PS, Friedman D, Lafrancois JJ, Iyengar SS, Fenton AA, Maclusky NJ, Scharfman HE (2014) Spike-wave discharges in adult Sprague-Dawley rats and their implications for animal models of temporal lobe epilepsy. Epilepsy Behav 32:121-131. CrossRef Medline

Pi HJ, Hangya B, Kvitsiani D, Sanders JI, Huang ZJ, Kepecs A (2013) VIP disinhibitory and preferentially activated by sensory input: cortical interneurons that specialize in disinhibitory control. Nature 503:521-524. CrossRef Medline

Porter JT, Cauli B, Tsuzuki K, Lambolez B, Rossier J, Audinat E (1999) Selective excitation of subtypes of neocortical interneurons by nicotinic receptors. J Neurosci 19:5228-5235. Medline

Sasa M, Ohno Y, Ujihara H, Fujita Y, Yoshimura M, Takaori S, Serikawa T, Yamada J (1988) Effects of antiepileptic drugs on absence-like and tonic seizures in the spontaneously epileptic rat, a double mutant rat. Epilepsia 29:505-513. CrossRef Medline

Schroeder CE, Lakatos P (2009) Low-frequency neuronal oscillations as instruments of sensory selection. Trends Neurosci 32:9-18. CrossRef Medline

Seneviratne U, Cook M, D'Souza W (2014) Focal abnormalities in idiopathic generalized epilepsy: a critical review of the literature. Epilepsia 55:1157-1169. CrossRef Medline

Smart TG (1987) Single calcium-activated potassium channels recorded from cultured rat sympathetic neurones. J Physiol 389:337-360. CrossRef Medline

Snead OC 3rd (1991) The gamma-hydroxybutyrate model of absence seizures: correlation of regional brain levels of gamma-hydroxybutyric acid and gamma-butyrolactone with spike wave discharges. Neuropharmacology 30:161-167. CrossRef Medline

Steriade M, Deschênes M, Domich L, Mulle C (1985) Abolition of spindle oscillations in thalamic neurons disconnected from nucleus reticularis thalami. J Neurophysiol 54:1473-1497. Medline

Steriade M, McCormick DA, Sejnowski TJ (1993) Thalamocortical oscillations in the sleeping and aroused brain. Science 262:679-685. CrossRef Medline

Strohl KP, Gallaugher L, Lynn A, Friedman L, Hill A, Singer JB, Lander ES, Nadeau J (2007) Sleep-related epilepsy in the A/J mouse. Sleep 30:169176. Medline
Suntsova N, Kumar S, Guzman-Marin R, Alam MN, Szymusiak R, McGinty D (2009) A role for the preoptic sleep-promoting system in absence epilepsy. Neurobiol Dis 36:126-141. CrossRef Medline

Tamás G, Lorincz A, Simon A, Szabadics J (2003) Identified sources and targets of slow inhibition in the neocortex. Science 299:1902-1905. CrossRef Medline

Tao JX, Chen XJ, Baldwin M, Yung I, Rose S, Frim D, Hawes-Ebersole S, Ebersole JS (2011) Interictal regional delta slowing is an EEG marker of epileptic network in temporal lobe epilepsy. Epilepsia 52:467-476. CrossRef Medline

Traub RD, Jefferys JG, Miles R, Whittington MA, Tóth K (1994) A branching dendritic model of a rodent CA3 pyramidal neurone. J Physiol 481: 79-95. Medline

Traub RD, Contreras D, Cunningham MO, Murray H, LeBeau FE, Roopun A, Bibbig A, Wilent WB, Higley MJ, Whittington MA (2005) Singlecolumn thalamocortical network model exhibiting gamma oscillations, sleep spindles and epileptogenic bursts. J Neurophysiol 93:2194-2232. CrossRef Medline

Tsuneki H, Salas R, Dani JA (2003) Mouse muscle denervation increases expression of an alpha7 nicotinic receptor with unusual pharmacology. J Physiol 547:169-179. CrossRef Medline

Van Duijn H, Schwartzkroin PA, Prince DA (1973) Action of penicillin on inhibitory processes in the cat's cortex. Brain Res 53:470-476. CrossRef Medline

van Luijtelaar G, Behr C, Avoli M (2014) Is there such a thing as "generalized” epilepsy? Adv Exp Med Biol 813:81-91. CrossRef Medline

Vucurovic K, Gallopin T, Ferezou I, Rancillac A, Chameau P, van Hooft JA, Geoffroy H, Monyer H, Rossier J, Vitalis T (2010) Serotonin 3A receptor subtype as an early and protracted marker of cortical interneuron subpopulations. Cereb Cortex 20:2333-2347. CrossRef Medline

Williams M, Robinson JL (1984) Binding of the nicotinic cholinergic antagonist, dihydro-beta-erythroidine, to rat brain tissue. J Neurosci 4:29062911. Medline

Yan D, Meyer JK, White MM (2006) Mapping residues in the ligandbinding domain of the $5-\mathrm{HT}_{3}$ receptor onto d-tubocurarine structure. Mol Pharmacol 70:571-578. CrossRef Medline

Yasuhara A, Yoshida H, Hatanaka T, Sugimoto T, Kobayashi Y, Dyken E (1991) Epilepsy with continuous spike-waves during slow sleep and its treatment. Epilepsia 32:59-62. CrossRef Medline 